Cita bibliográfica: Pérex Herranz, F.M. (2018). Atrapar el «gesto», proseguir la investigación. El papel de los contextos determinantes en las ciencias. [Catch the "gesture", continue the investigation. The role of determinant contexts in science]. PHI. Revista internacional de Filosofía Contemporánea y Filosofía de la Imagen, 0, 9-55.

\title{
ATRAPAR EL «GESTO», PROSEGUIR LA INVESTIGACIÓN. EL PAPEL DE LOS CONTEXTOS DETERMINANTES EN LAS CIENCIAS
}

\author{
CATCH THE "GESTURE", CONTINUE THE INVESTIGATION. \\ THE ROLE OF DETERMINANT CONTEXTS IN SCIENCE
}

\author{
Fernando Miguel Pérez Herranz \\ Universidad de Alicante
}

\section{Resumen}

La Teoría del Cierre Categorial es una filosofía de la ciencia propuesta por Gustavo Bueno. En este artículo se presenta uno de los conceptos básicos de la teoría: el contexto determinante. Se define por contraposición al concepto formalista de Mathesis Universalis (la inconmensurabilidad de las verdades científicas pueden ser peligrosa para la vida del propio hombre) y al concepto equívoco de paradigma (cabe cualquier cosa, no solo lo científico: lo artístico, lo religioso, lo político...)

Palabras clave: contexto determinante, modelización, Mathesis Universalis, paradigma.

\begin{abstract}
The Theory of Categorical Closure is a philosophy of science proposed by Gustavo Bueno. In this paper one of the basic concepts of that theory is presented: the determining context. It is defined by contraposition to the formalist concept of Mathesis Universalis (the incommensurability of scientific truths can be dangerous for the life of man himself) and the equivocal concept of paradigm (everything fits in, not only scientific matters, but also artistic, religious, political...).
\end{abstract}

Keywords: determining context, modeling, mathesis universalis, paradigm. 
Índice

\section{Presentación}

1. De la materia y la forma

2. Canon morfológico: sujeto operatorio

3. Teoría del Cierre Categorial

EJES DE LA ESTRUCTURA TRIÁDICA

PLURALIDAD E INCONMENSURABILIDAD DE LAS CIENCIAS

OPERACIONES DE TOTALIZACIÓN

PLURALIDAD CATEGORIAL

VERDAD SINTÉTICA

CONTEXTO DETERMINANTE

4. Los géneros de la ciencia moderna: del Orden del cosmos (Aristóteles) a la desconexión potentia Dei absoluta y potentia Dei ordinata (Escoto y Ockham)

LOS PRINCIPIA MEDIA Y LAS ARMADURAS

GÉNESIS DE LOS CONTEXTOS DETERMINANTES

DEFINICIÓN DE «CONTEXTO DETERMINANTE»

CONTEXTOS DETERMINANTES ADVERSUS PARADIGMAS

\section{Contextos determinantes clásicos}

«EL TRIÁNGULO» EN TALES DE MiLETO

«EL CÍRCULO» EN LOS ELEMENTOS DE EUCLIDES

«EL GNOMÓN» DE ANAXIMANDRO

7. Otros contextos de modelización

LA TEORÍA DE LAS CATÁSTROFES DE RENÉ THOM

EL MÉTODO DE TRIANGULACIÓN

El Sistema de PERÍODOS PARA LOS ELEMENTOS

AUSENCIA DE CONTEXTOS DETERMINANTES EN LA NEUROCIENCIA

8. Los límites de la TCC: entre la gnoseología materialista y la epistemología fenomenológica 


\section{Presentación}

Al inicio de los años ochenta del pasado siglo xx, Gustavo Bueno (en adelante, GB) presentó en sociedad una filosofía de las ciencias — conocida como Teoría del Cierre Categorial - en el I Congreso de Teoría y Metodología de las Ciencias. ${ }^{1}$ En la década de los noventa desplegó aquel proyecto y publicó cinco volúmenes de los quince que había programado. ${ }^{2}$ Era una alternativa a los enfoques formalista positivista y analítico de cuño anglosajón y al epistemológico estructuralista de cuño francés. Siempre he lamentado la interrupción de aquella investigación, porque me pareció que algunos de los conceptos que utilizaba GB permitían comprender de manera especial una de las cuestiones más sorprendentes de la obra del ser humano: la construcción de enunciados universales a partir de operaciones particulares, en general, más bien rudimentarias, toscas y aun vulgares («El mundo de la vida»).

\section{De la materia y la forma}

La Teoría del Cierre Categorial (TCC) es una teoría crítica, que, desde sus propios presupuestos - la distinción materia / forma - se define respecto de las teorías que sobrevaloran la forma sobre la materia (posición que, en general, denomina teoreticismo, defendido desde diferentes perfiles por Képler, Kant, Hilbert, Popper...); la materia sobre la forma (descripcionismo: Bacon, Husserl, Schlick, Mach...); o la yuxtaposición de materia y forma (adecuacionismo: Tomás de Aquino, Leibniz, Tarski, Kuhn.....). ${ }^{3}$ La posición de GB, el circularismo, conjugaría materia y forma según el esquema aristotélico que descarta tanto una materia como una forma absolutas: lo que es material respecto de alguna forma, puede ser formal respecto de otros contenidos:

Además, la materia es algo relativo, pues para una forma se requiere una materia, y para otra forma, otra materia (éti tôn prós ti he hyle, állo gàr eidei álle hyle). (Física, 2, 194b8-9)

No hay una acribia, una delimitación tajante, entre materia y forma. El propio Aristóteles recurre a ejemplos:

\footnotetext{
${ }^{1}$ Gustavo Bueno, "El cierre categorial aplicado a las ciencias físico-químicas", Actas el I Congreso de Teoría y Metodología de las ciencias, Oviedo, Pentalfa, 1982, pp. 101-175. Más adelante apareció otro artículo dedicado a las ciencias humanas: "En torno al concepto de «ciencias humanas». La distinción entre metodologías $\alpha$ operatorias y $\beta$-operatorias", El Basilisco, 2 (1978), pp. 12-46.

${ }^{2}$ Gustavo Bueno, Teoría del cierre categorial, 1-5 vols., Pentalfa, Oviedo, 1992-93. Se cita en el texto entre corchetes: TCC, seguido del volumen y la página. Presentaciones reducidas de la teoría en ¿Qué es la ciencia?, Oviedo, Pentalfa, 1995. La función actual de la ciencia, Universidad de las Palmas de Gran Canaria, 1995.

${ }^{3}$ Naturalmente, teniendo presentes todos los matices pertinentes entre las distintas doctrinas de estos filósofos.
} 
Quizás lo necesario se encuentra también en el concepto de una cosa. Pues si definimos la operación de aserrar como un cierto tipo de división, tal división no se podrá cumplir si la sierra no tiene determinado tipo de dientes, y estos dientes no podrán ser tales si la sierra no está hecha de hierro. Porque también en el concepto hay ciertas partes que son como su materia. (Física, II, 9, 200b 5-8)

El circularismo se define directamente contra el adecuacionismo armonista por su pretensión de unir externamente materia y forma. Las otras dos posiciones no serían sino ensayos o intentos de radicalización para definir la ciencia: pura forma desconectada de la materia; o pura materia desconectada de la forma. El circularismo estaría negando, a la vez, la materia y la forma, al entenderlas como partes que se conjugan entre sí: la materia como forma y la forma como materia. Pues se reconoce que ni la materia — los hechos, los datos, las experiencias... — ni la forma —el silogismo, los sistemas formales, las teorías...— pueden estar ya prefigurados, sino que las formas son los cursos mismos que vinculan las partes constitutivas de la materia, de tal modo que es imposible hablar tanto de una forma universal (lógica, matemática...) como de una materia universal (éter, plenum...).

Ahora bien, si la materia y la forma no están dadas de antemano, entonces han de ser resultados de construcciones de algún sujeto operatorio que los establezca. Un sujeto que, por definición, no puede ser ni Dios ni el Ser ni una Conciencia trascendental. Se descartan, por tanto, la hipóstasis del Entendimiento Agente Universal de tipo averroísta o de una Conciencia que comprenda a todos los individuos (Goethe: «Sólo entre todos los hombres puede vivirse lo humano») o de una Conciencia Pura (subjetivista) de tipo cartesiano en epistemología o kantiana en filosofía práctica. (La TCC hereda de Kant la concepción de los enunciados científicos como síntesis, como juicios sintéticos a priori; pero descarta el sujeto trascendental del imperativo categórico). Podríamos preguntarnos, entonces, por las condiciones en las que se desenvuelve la TCC a través de este sujeto operatorio.

La primera condición tendría que ver con lo que he llamado en otra ocasión la sabiduría de Occidente: ${ }^{4}$ una sociedad de profesionales que necesitan del contacto con la realidad y la verdad, y no solo con la significación. Una sociedad heredera del Oriente, familiarizado con las técnicas de la metalurgia ${ }^{5}$ y de los trabajos ejercidos por artesanos

\footnotetext{
${ }^{4}$ F. M. Pérez Herranz, "La eliminación de la subjetividad de los fines. Platón y las matemáticas", Eikasía, 12, extraordinario - Platón (2007), pp. 203-236.

${ }^{5}$ Las sociedades del cuarto milenio aC, y tras los grandes descubrimientos del Neolítico: la industria del metal (cobre), etc., se organizaban en torno a una ontología del trabajo y del arte. Véase, por ejemplo, Eleuterio Elorduy (col. J. Pérez Alonso), El estoicismo, 2 vols., Madrid, Gredos, 1972.
} 
pertenecientes a un segmento social intermedio entre los aristócratas guerreros y el campesinado, que cristalizarán, a lo largo del tiempo, en artesanos, ingenieros — civiles y militares—, «trabajadores de lima», médicos, mercaderes, abogados... Y, cuando se trata de establecer sus relación con la verdad, también sabios (sophós), profesores — sofistas, académicos...-, ontoteólogos, filósofos...

La segunda condición estaría en relación con la ética prudencial de los cuerpos humanos recortados a escala racional operatoria. Dicho rápidamente: la distinción entre el bien y el mal dependería de su vínculo con el cuerpo individual, de modo que la muerte sería el mal ético por antonomasia, el límite de la propia ética.

Para GB el sujeto de la ciencia, mediado por el sujeto técnico, artesanal, coincide con el sujeto prudencial que ha de tomar decisiones morales entre lo bueno y lo malo (no podemos entrar aquí en el concepto de kathekon, que será traducido por officium, lo que ahora llamaríamos deber): ${ }^{6}$

Pero si toda ciencia es operatoria, toda ciencia será, en sus orígenes, práctica y, por tanto, la misma ciencia teorética, aunque no sea una de las ciencias morales, deberá ejercitar también, de algún modo, la prudencia y la sindéresis, es decir, podrá tomar ya de su propia experiencia el significado de lo bueno y de lo malo. ${ }^{7}$

En consecuencia, la cuestión nuclear no es ya la de si la ciencia es necesaria o no para los seres humanos, sino: ¿qué tipo de ciencia nos conviene más, si es que es posible hablar de diversas ciencias? ${ }^{8}$

\section{Canon morfológico: sujeto operatorio}

Estas condiciones obligan a tener presente en cualquier análisis de las ciencias al sujeto operatorio que las formula (técnico-artesanal y prudencial), lo que comporta

\footnotetext{
6 "Max Pohlnz opina que Zenón extrajo del patrimonio espiritual semítico el concepto de «mandamiento», tan familiar a los judíos, creando el concepto de kathekon mediante el injerto de la noción de mandamiento sobre el concepto griego de physis, lo cual resulta verosímil. Lo cierto es que Zenón y el Pórtico, al elaborar el concepto de kathekon, otorgaron a la historia espiritual de Occidente una aportación de primera magnitud: en sus diversas versiones, el concepto de «deber» se ha transformado en una auténtica categoría del pensamiento moral occidental". G. Reale y D. Antiseri, Historia del pensamiento filosófico y científico, I, Madrid, Herder, 1988, p. 235.

${ }^{7}$ Gustavo Bueno, El sentido de la vida, Oviedo, Pentalfa, 1996, p. 23.

${ }^{8} \mathrm{Cfr}$. los argumentos que utiliza Pablo Huerga $i$ Que piensen ellos! Cuestiones sobre materialismo y relativismo, Barcelona, El Viejo Topo, 2003.
} 
consecuencias enormes y decisivas no solo para las representaciones que nos hacemos de las ciencias, sino también para su propio ejercicio. Pues si se supone, por ejemplo, que las ciencias son resultados de verificaciones de hipótesis, es cierto que cuantas más hipótesis se realicen, sean gratuitas o absurdas, más posibilidades habrá de que alguna de ellas coincida con la realidad. Sin embargo no parece que sea por acumulación de hipótesis como funcionan las ciencias. Precisamente la TCC nos muestra que son ciertos artilugios —que GB llama contextos determinantes o armaduras y que nosotros denominamos también contextos de modelización ${ }^{9}$ o contextos gnómicos- ${ }^{10}$ los que permiten la construcción de los teoremas científicos, unos contextos que están dados a escala del sujeto operatorio (insistimos, técnico y prudencial). La ciencia, por decirlo rotundamente, no es la ciencia de Dios, sino la ciencia de los hombres. No se puede aceptar, por ejemplo, la idea, tan cargada de consecuencias, de Filón de Alejandría (25aC-50dC), según la cual Moisés es el filósofo por antonomasia en cuanto «intérprete de Dios»; y puesto que Dios es la única fuente de cuanto existe, Moisés, su intérprete, es el maestro de toda ciencia humana. Pero tampoco es ciencia de la imaginación o de la fantasía (en su sentido clásico), de la pura subjetividad, que pretenda subsumir a la naturaleza bajo las categorías del puro deseo: por ejemplo, levantar un puente de hierro que conecte a todos los planetas, como denuncia la irónica caricatura de J. J. Grandville / Jean Ignace Gérard (1803-1847). (Fig. 1)

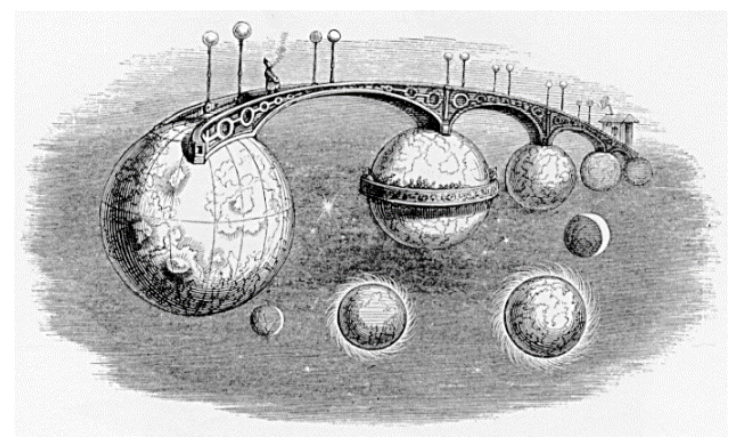

Fig. 1. Grandville, Le Pont des planètes. 1844.

La ciencia es ciencia de artilugios — armaduras dice a veces GB - construidos mediante operaciones técnicas humanas. Las ciencias, como ya sabían desde Wilhelm Dilthey a Georges Canguilhem, nacen de las técnicas:

\footnotetext{
${ }^{9}$ Un nombre que hemos encontrado en el artículo de David Calvo, "Los tres contextos de la investigación científica: descubrimiento, modelización y justificación". En Andrés Rivadulla (ed.), Hipótesis y verdad en ciencia. Ensayos sobre la filosofía de Karl R. Popper, Madrid, Editorial Complutense, 2004, pp. 179-191.

${ }^{10} \mathrm{El}$ hecho de ser el gnomón uno de los primeros contextos de modelización conocidos me ha llevado a utilizarlo como término genérico para este tipo de contextos fundamentales en la construcción del conocimiento científico. (véase infra)
} 
Y si la ciencia nace de las técnicas, las técnicas, a su vez, son un fenómeno biológico universal (así por ejemplo lo considera la biónica) y no solamente como una operación intelectual del hombre, de un conocimiento teórico que se aplica aquí o allá. ${ }^{11}$

Para hacer ciencia no hay que ponerse en el punto de vista de Dios (o de sus vicarios), ni en el de un Ego trascendental deseante, sino en el de un ego conformado a escala del cuerpo humano, con todos sus vigores y sus debilidades. Y esos cuerpos humanos establecen un límite a su posible saber (Ignoramus, ignorabimus). ${ }^{12}$ Por lo tanto, no puede haber operaciones que abarquen el Universo entero, y sus resultados solo pueden expresar estructuras de cuerpos dados in medias res, en cuanto morfologías que se aproximan o se alejan de la escala del cuerpo humano, pero sin anularlo por negación o identificación con el cosmos. La pretensión de aplicar la ciencia a la totalidad del Mundo [TCC, vol. 1, p. 250] podría dar origen a algunas atrayentes y atractivas cosmologías metafísicas (lo que permite explicar las diferencias entre teorías científicas como la gravitación y cosmologías especulativas como el Big-Bang), pero las verdades científicas por su propia naturaleza de construcciones humanas sólo pueden abrir determinadas franjas de verdad donde se configuran las primeras expresiones de identidad sintética; franjas que no son uniformes, sino que pueden ser más anchas o más estrechas, más profundas o más superficiales, más precisas o más borrosas, pero que no tienen por qué ser claras y distintas. El error y la oscuridad constituyen el horizonte perpetuo de las ciencias. Como las identidades se construyen frente a otras conexiones posibles, esas alternativas (errores) sólo pueden ser eliminadas tras nuevas y más poderosas construcciones [TCC, vol 1, p. 180]. Esto nos permite extender el concepto de verdad científica a situaciones límites según la analogía o según ciertas relaciones formales, pero la determinación de tales identidades es mínima, incluso nula, porque el razonamiento es analógico y no cierra categorialmente. La verdad analógica no es unívoca y, entonces, la ciencia desemboca en filosofía.

La concepción de este tipo de sujeto operatorio se encuentra dentro de la tradición renacentista hispanoportuguesa — Raimundo Sabunde, Luis Vives, João de Barros, Gómez Pereira, Miguel Sabuco, Juan Huarte de San Juan, y tantos otros, ${ }^{13}$ — asociada más a la

\footnotetext{
${ }^{11}$ Georges Canguilhem, El conocimiento de la vida, Barcelona, Anagrama, 1976, p. 148.

${ }^{12}$ Un eslogan de Emil Heinrich Du Bois Reymond, y que le sirve a GB como título a un artículo muy penetrante en El Basilisco, 4 (1990), pp. 69-88.

${ }^{13}$ Raimundo Sabunde / Ramón Sibiuda (1385-1436), Diálogos de la naturaleza del hombre; Luis Vives (14931534), De anima et vita (1538); João de Barros (1496-1570), Ropicapnefma (1532); Gómez Pereira (1500-1558),
} 
medicina que a la astronomía, y que habría ido dibujando las líneas maestras de un «cuerpo humano» novedoso, al asimilar progresivamente los predicados espirituales característicos del alma. Ahora bien, la escala corpórea es escala morfológica, es decir, el cuerpo ha de estar especificado, porque somos morfologías dadas entre otras morfologías. Y así, habrá morfologías que nos atraen y otras que nos repelen: "Evidentemente hay fisionomías que nos inspiran, no se sabe por qué, una invencible repugnancia"; ${ }^{14}$ y otras que nos espantarían si nos reconociéramos en ellas. (Fig. 2)

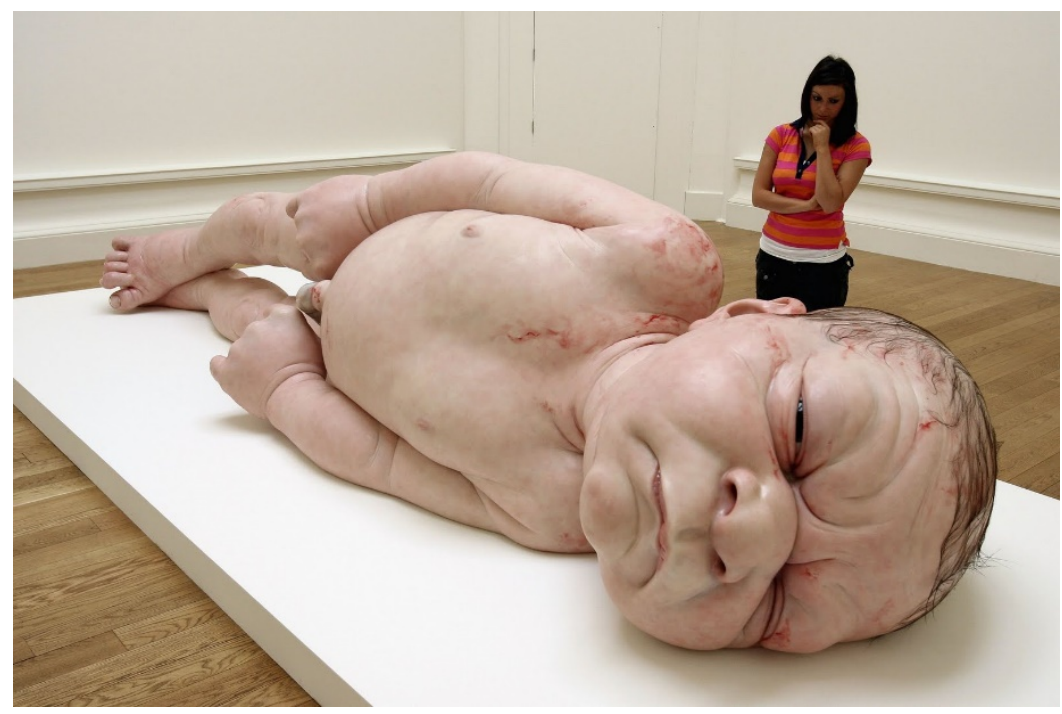

Fig. 2. La obra de Ron Mueck muestra por contraposición la escala corpórea humana

Hay morfologías que nos son más cercanas, como los sólidos; y otras que nos son más alejadas, como los fluidos: ${ }^{15}$

C'est aussi la raison pour laquelle la Mécanique des Solides nous est infiniment mieux connue que la Mécanique des Fluides. ${ }^{16}$

En definitiva, los elementos de la TCC se han de componer alrededor de un sujeto operatorio que es un sujeto morfológico. La potencia de esta idea me ha llevado a llamar a mi propio ejercicio morfologismo filosófico, por cuanto la ontología del mundo se define por relaciones entre morfologías (Ni entre ideas ni entre materias: las materias han de estar

Antoniana Margarita, (1554); Miguel Sabuco (1525-1588), Nueva filosofía de la naturaleza del hombre (1587), Juan Huarte de San Juan (c. 1530-1589), Examen de ingenios para las ciencias (1575);..

${ }^{14}$ Fiodor Dostoievski, El eterno marido, México, Océano, 1982, p. 12.

15 "Autre aspect du refus de dévaluer la perception, Thom maintient à la géométrie euclidienne, petite province des mathématiques, une importance primordiale dans la philosophie de la nature. Elle a des connexions avec l'expérience des solides et des leurs mouvements, pratiquée par chacun, quoique ses objets ne se rencontrent dans le monde que par approximation". J. Largeault, "Préface" a Apologie du Logos, p. 25.

${ }^{16}$ René Thom, Modèles mathématiques de la morphogenèse, París, Bourgois, 1980, p. 201. 
especificadas siempre como morfologías. El tema de los monstruos como límites de las morfologías es muy común en la literatura desde su mismo origen en la Ilíada).

\section{Teoría del Cierre Categorial}

Teniendo presente estos dos postulados - los contextos determinantes o de modelización y el sujeto morfológico operatorio-, recordemos rápidamente algunos elementos de la TCC. La Gnoseología analítica ${ }^{17}$ está configurada según una estructura triádica, alrededor de tres ejes entre los cuales se distribuyen las partes formales o figuras de las diversas ciencias. Esta distribución está inspirada en las estructuras de «los lenguajes de palabras» según la clasificación clásica de Charles Morris: semántica, sintaxis y pragmática. ${ }^{18}$

\section{EJES DE LA ESTRUCTURA TRIÁDICA}

El eje sintáctico (relación entre signos), a su vez, se divide en términos, operaciones y relaciones. Los términos o partes formales de una ciencia, que han de ser, al menos, dos (por eso la teología natural, como ciencia definida respecto de un objeto —Dios- es absurda). Los términos (clases de términos) se vinculan por relaciones de semejanza o isología y de contigüidad o sinexión — términos que siendo diversos están entrelazados necesariamente-. Los términos son entidades primitivas atómicas, no en su sentido ontológico, sino en la medida en que se combinan con otros términos, constituyendo así el campo material de cada disciplina.

Las operaciones o transformaciones que un objeto experimenta bajo la acción de un sujeto operatorio y que, por las mismas razones, han de ser como mínimo dos. Las operaciones se caracterizan de dos modos: o bien como propiedades — si se tiene en cuenta la disposición de los componentes y no el término resultante de la oración, que queda segregado-, o bien como aspectos —si se tiene en cuenta el término resultante de la operación en cuanto disociado—. Además, ciertos instrumentos —-microscopios, telescopios, estereoscopios, etc. - han de ser definidos como operadores y no como expansiones de los

\footnotetext{
17 Gustavo Bueno, Estatuto Gnoseológico de las Ciencias Humanas, sección III, Gnoseología Analítica, Fundación Juan March, 1976, pp. 319ss.

${ }^{18}$ Charles Morris, Fundamentos de la teoría de los signos, Barcelona, Paidós-Comunicación, 1985.
} 
sentidos. Las operaciones (manuales y mentales) aproximan y separan, ${ }^{19}$ lo que hace que el enclasamiento implique que las operaciones sean teleológicas, y las estrategias de los cursos operatorios tengan que ver con prolepsis (anticipaciones) y anamnesis (recuerdos). Es decir, que los términos compuestos o disociados no se componen o disocian por sí mismos y, en consecuencia, las operaciones son de carácter sintético. Como las operaciones se dan entre términos apotéticos (a distancia) y, en tanto que repetibles, son normativas, todas las ciencias comienzan siendo normativas, pues en sus orígenes han de ser prácticas, hay que ejercer de algún modo la prudencia o sindéresis, como quedó dicho.

Y, por último, las relaciones necesarias que se establecen entre los objetos por medio de esas operaciones.

El eje semántico, que afecta principalmente a los términos y a las relaciones, se divide en referencias, fenómenos y estructuras. Las referencias son necesarias para que sea efectiva la operatividad. Ahora bien, los hechos empíricos o datos fisicalistas, una vez desconectados del resto de materialidades encarnadas en una totalidad concreta, devienen fetiches, simulacros, ilusiones. Los fenómenos son los objetos apotéticos sobre los que se llevan a cabo las operaciones de separar o de aproximar (análisis y síntesis). Y las esencias o estructuras resultan de la eliminación o neutralización de los sujetos.

El eje pragmático se divide en normas, dialogismos y autologismos. Las normas se emparejan a las reglas de la lógica formal. Los dialogismos tienen que ver con los debates, transmisión de documentos, enseñanza, congresos, etc. entre los distintos sujetos de una comunidad científica. Y los autologismos, con las relaciones del sujeto consigo mismo: la memoria, los recuentos, los sueños... ${ }^{20}$

\footnotetext{
19 Según el aforismo de Francis Bacon: "Toda la industria del hombre estriba en aproximar las sustancias naturales unas a otras o en separarlas; el resto es una operación secreta de la naturaleza", Novum organum, I,3. En este sentido escribe Rodolfo Mondolfo: "La geometría, por lo tanto, es demostrable, porque las líneas y las figuras acerca de las cuales razonamos, son trazadas y descriptas por nosotros mismos; y la filosofía civil es también demostrable porque somos nosotros mismos los que hacemos la sociedad". Verum factum, México, Siglo XXI, p. 62. Y también Luis Fernández Galiano: "Tal como rezaba la divisa de los antiguos químicos, ignis muta res. El fuego opera alteraciones y metamorfosis en la fragua del herrero y el crisol del alquimista; en el horno del fabricante, el fuego transforma el mineral en material. El fuego cuece el barro, genera el metal, fabrica el vidrio. En el hogar, el fuego habitaba la construcción; en el horno, el fuego construye la habitación", El fuego y la memoria, Madrid, Alianza, 1991, p. 40.

20 "Un autor psicoanalítico puede defender el carácter flexible de la nueva teoría simbólica [freudiana] para, unas líneas más adelante, seguir considerando como un sueño sexual (puesto que las serpientes entrelazadas simbolizan el pene) el célebre sueño de la serpiente de Kekulé (en el cual, dos serpientes entrelazadas le proporcionaron la clave de la estructura anular de la molécula de benzol que perseguía hacía tiempo". D.E. Zimmer, Dormir y soñar, Barcelona, p. 184.
} 
La objetividad científica -y pasamos a la gnoseología sintética- exige la neutralización o segregación de los componentes subjetuales (todo el eje pragmático, las operaciones y los fenómenos) para alcanzar los componentes objetuales —fundamentalmente términos que van apareciendo en el campo como resultantes de las operaciones del sujeto- y los componentes proposicionales —fundamentalmente las relaciones y las esencias o estructuras-. Comprobémoslo con la demostración del teorema de Pitágoras según la estrategia que al de Samos le atribuye J. Bronowski. ${ }^{21}$ En primer lugar, se segregan los componentes subjetuales — las manipulaciones de los pitagóricos con azulejos sobre la arena...- ; después, se construyen los componentes objetuales -figuras planas diversas: ángulos, triángulos, cuadrados...-; y, por último, se establece una asombrosa relación (de identidad): «La suma de los cuadrados de los catetos es igual al cuadrado de la hipotenusa». De esa relación quedan marginados contenidos como el color de las figuras, el tiempo que se tarda en trazarlas, etc. (Fig. 3)
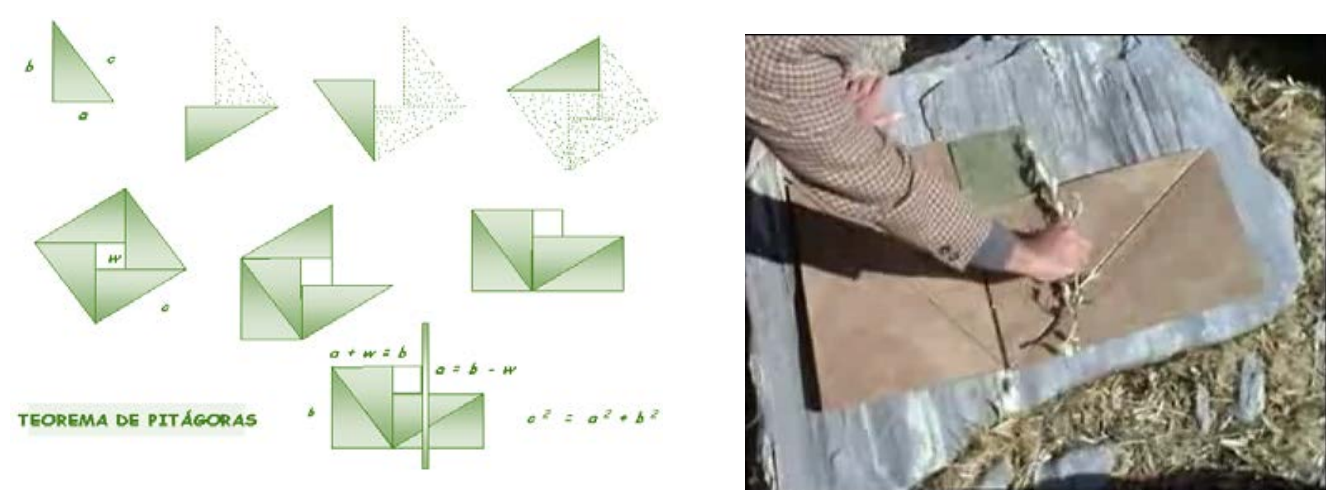

Fig. 3. Teorema de Pitágoras Estrategia de la demostración según J. Bronowski.

En definitiva, la ciencia puede concebirse como una serie de cursos constructivos a partir de operaciones de un sujeto sobre un material dado y ya elaborado de alguna manera. (Recordemos que lo material respecto de una forma puede ser forma para otra materia, en el sentido mencionado de Aristóteles). ${ }^{22}$

\section{PLURALIDAD E INCONMENSURABILIDAD DE LAS CIENCIAS}

\footnotetext{
${ }^{21}$ Jacob Bronowski, El ascenso del hombre, Fondo Educativo Interamericano, 1979, p. 159.

${ }^{22}$ A modo de ilustración: la teoría del cristal es forma respecto de la cristalografía, pero materia para la mineralogía. Cfr. Evaristo Álvarez, "La construcción de la geología como ciencia: un análisis desde la teoría del cierre categorial", El Basilisco, 23 (1998), pp. 3-30.
} 
GB arranca del siglo XIX y no, como es tan habitual, del siglo XVII. Indudablemente admite que el primer cierre categorial es el que realiza Newton. ${ }^{23}$ Pero el factum de las ciencias, como fenómeno institucional, es, a partir del siglo XIX, un fenómeno plural que desborda la mecánica: la termodinámica (Boltzmann), el electromagnetismo (Maxwell) o la química (Dalton) se presentan irreductibles a la mecánica newtoniana. Una pluralidad que, por cierto, obligó a pensar la propia ciencia como problema, a desarrollar la filosofía de la ciencia — Whewell, Comte, Brentano—, ${ }^{24}$ más allá de la clásica filosofía de la naturaleza. Al no haber ningún sustrato común a todas las ciencias, se hizo obligado defender la existencia de múltiples verdades que, incluso, pudieran entrar en conflicto y contradicción. Una pluralidad ya fue conocida por Aristóteles al distinguir la Aritmética de la Geometría y considerarlas irreductibles: ${ }^{25}$

Por tanto no es posible, pasando de un género a otro, por ejemplo, demostrar lo geométrico por la aritmética. (Primeros Analíticos, 75a38,75b4; cf. también Met, 1020a10)

Desde el siglo XIX la inconmensurabilidad es un fenómeno generalizado, por lo que se ha de rechazar una filosofía armonista de la ciencia, que considere la totalidad del mundo como un puzzle de múltiples piezas que se ajustan a medida que se desarrolla cada una de las ciencias. Al contrario, las ciencias entran en conflictos, en desarmonías, en inconmensurabilidades y pueden poner en riesgo otras ciencias como ocurrió con la explosión de la bomba atómica que destruyó el posible estudio de los corales de las islas Bikini, y, en el límite, la destrucción del propio mundo.

\section{OPERACIONES DE TOTALIZACIÓN}

\footnotetext{
${ }^{23}$ G. Bueno, "Ignoramus, ignorabimus! (en torno al libro de Ferdinando Vidoni)", p. 70.

${ }^{24}$ Cf. Alberto Hidalgo, Gnoseología de las Ciencias de la Organización Administrativa, Universidad de Oviedo, 1989.

25 "Tenemos, en consecuencia, que relaciones cuyo nombre es el mismo —igual, mayor, menor- tienen significados distintos e «irreductibles» en Aritmética y en Geometría. Por esta razón, ambos mundos —el numeral y el extensivo-, ambas ciencias - la Aritmética y la Geometría - se separaron en tiempos de Aristóteles $\{\S 4\}$. No cabía, salvo los principios formales de la lógica, descubrir ningún principio común a ambas materias. Este hecho corroboró a Aristóteles en las razones que ya tenía para formular la ley de la «incomunicabilidad de los géneros», ley que iba a dejar el globo intelectual dividido formalmente, y no por accidencia, en una pluralidad de ciencias, irreductibles las unas a las otras. Mientras cada ciencia parte de una «intuición básica», queda encerrada dentro de ella, encajonada, con las raíces presas allí, sierva de su gleba intuitiva". José Ortega y Gasset, "La idea de principio en Leibniz", Obras completas, Madrid, Alianza, 1983, VIII, p. 98.
} 
La clave de la TCC, por tanto, se encuentra en establecer las operaciones que realiza ese sujeto dado a escala corpóreo-morfológica. Los teoremas de las ciencias serán, necesariamente, resultado de operaciones mano-cerebro. Anaxágoras decía que «el hombre piensa porque tiene manos». Giordano Bruno en La expulsión de la Bestia Triunfante: «La Providencia ha decretado que el hombre esté ocupado en la acción a través de las MANOS y en la contemplación a través del INTELECTO, de tal forma que no podría contemplar sin acción o trabajar sin contemplación». Y Fernán Pérez de Oliva en el Diálogo de la dignidad del hombre:

De las cosas que ya dichas tengo puedes conoscer, Aurelio, que no es el hombre desamparado de quien el mundo govierna, como tú dixiste; mas antes bastecido más que otro animal alguno, pues le fueron dados ENTENDIMIENTO y MANOS para esto bastantes, y todas las cosas en abundancia de que se mantuviese.

Las operaciones aproximan o separan, totalizan o dividen. Pero las operaciones de totalización y división son de muchas clases: totalizaciones atributiva y distributiva, porfiriana y combinatoria, etc. ${ }^{26}$ Los todos se componen de partes que GB ha analizado con precisión. Entre otras, establece las partes formales, materiales o conformadas de un todo.

- Partes formales: aquéllas cuya morfología supone genética o estructuralmente la morfología del todo. Así, las partes de un jarrón quebrado que conserva de algún modo la forma del todo, pero sólo a efectos de reconstrucción por ajuste sinalógico (por contigüidad) con otros fragmentos.

- Partes materiales: aquéllas cuya morfología no mantiene de ningún modo la forma del todo. Así, las partículas de un jarrón pulverizado. Las partes materiales pueden ser: determinantes, constituyentes e integrantes. Por ejemplo: sea un cuadrado Q. Sus partes determinantes (multiplicativas) serán: cuadrilátero, paralelogramo y equilátero, por lo que $\boldsymbol{Q}$ $=\boldsymbol{C} \times \boldsymbol{P} \times \boldsymbol{E}$. Sus partes integrantes (aditivas y del mismo orden) serán: triángulos rectángulos isósceles, por lo que $\boldsymbol{Q}=\boldsymbol{t}_{\mathbf{1}}+\boldsymbol{t}_{\mathbf{2}}$. Sus partes constituyentes (de distinto orden) serán: lados y vértices. (Fig. 4)

\footnotetext{
${ }^{26}$ Gustavo Bueno, "Todo y parte", Cuadernos del Norte, 50 (1988), pp. 123-135.
} 


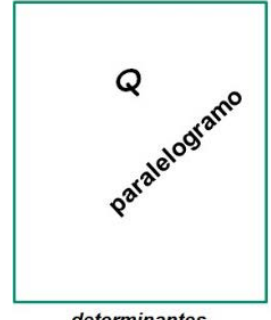

determinantes
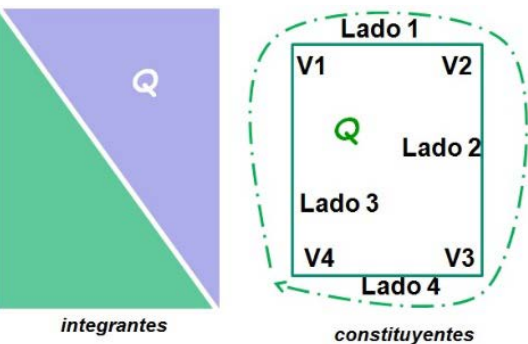

Fig. 4. Partes a totalizar

- Partes conformadas (proto-formales): aquéllas que se definen respecto de las partes amorfas o no conformadas. No tienen por qué ser partes formales, aunque el todo sí presuponga la parte conformada, como las sustancias de la química, las masas planetarias... Aunque están más próximas a las partes materiales, son contenidos ya conformados, sin ser partes formales [TCC, vol. 3, p. 154]. Así, las caras triangulares de un tetraedro no son partes formales, pero sí son partes conformadas. Un todo efectivo puede redefinirse como un todo en tanto nos sea dado en función de sus partes formales.

- Partes recursivas: aquéllas que, dada una totalidad fenoménica, pueden re-aplicarse por semejanza a otras totalidades fenoménicas, aunque no a todas ellas. Este tipo de definición, como puede advertirse, remite a una teoría epistemológica más general. Frente a un nominalismo exagerado que considera las totalidades como agregados efímeros, se defiende aquí una posición realista-moderada. La gama de posiciones epistemológicas es, en cualquier caso, muy variada. Podemos señalar posiciones polares con sus respectivas modulaciones:

$a_{1}$ ) El nominalismo atomista o agregacionista, al modo de David Hume, niega todo sentido a los universales y a las totalidades fenoménicas que tengan pretensión de ser algo más que agregados efímeros, meros rótulos o nombres que engloban a los hombres en un supuesto común. Niega, por tanto, que las proposiciones tengan sentido cuando dejan de ser interpretados como hechos individuales.

$a_{2}$ ) El nominalismo holista, continuista o comunalista, más mitigado, al modo de Guillermo de Ockam, niega las partes fenoménicas en beneficio de la continuidad, porque suponen que los nombres introducen una separación de los individuos que ocultan las relaciones entre ellos. 
$b_{1}$ ) El realismo exagerado o isologismo metamérico o jorismático, al modo del platonismo, asigna a una totalidad (distributiva), supuesta preexistente, el fundamento de la isología entre lo que serán las participaciones o modelos materiales: Ideas, formas o paradigmas. Suele presuponer una mente divina o humana.

$b_{2}$ ) El realismo moderado o isologismo diamérico o ajorismático, más templado, al modo del aristotelismo, define unos términos frente a otros por participación atributiva. Es un tratamiento material, causal, de los términos. Este tipo de totalidad se constituye por repetición, una cuestión central en la filosofía de la ciencia. A través de la repetición se reconoce el orden — las cosas particulares son hoy iguales a como las encontramos ayer- y las simetrías — tras manipular un objeto vuelve a su figura originaria-, las estructuras de todo álgebra, así como el concepto de estabilidad estructural. Ya Kant (Crítica de la Razón Pura, B 446) distinguió entre Natur — leyes causales que podían ser irrepetibles- - y Welt leyes matemáticas de los fenómenos en los que hay géneros y especies, que implican repetición-. (Cuadro I)

\begin{tabular}{||l||l|l|}
\hline & $\begin{array}{l}\text { Partición } \\
\text { distributiva }\end{array}$ & Repetición \\
\hline \hline Isologismo (realismo) & Metamérico & Diamérico \\
\hline $\begin{array}{c}\text { Heterologismo } \\
\text { (nominalismo) }\end{array}$ & Atomista & Holista \\
\hline \hline
\end{tabular}

\section{Cuadro I. Recursividad}

Los tipos morfológicos que instauran los procesos de totalización son también muy abundantes. Entre ellos GB destaca dos que mencionamos por su interés gnoseológico: las totalidades sistáticas / sistemáticas y las totalidades homeoméricas / holoméricas. Recordamos los conceptos del primer par:

Las totalidades sistáticas, referidas al plano fenoménico, no se presentan a la observación como meros agregados, pues han de poseer alguna ley interna. Ya ironizaba Oskar Morgenstern que «una rodilla por sí sola nunca sale a pasear» y Galileo podía haber dicho que «Júpiter por sí solo nunca sale a dar vueltas alrededor del sol». Ahora bien, aunque sus partes se codeterminan atributivamente, se descarta en cualquier caso toda forma común, 
como defiende el hilemorfismo. Esta forma de totalización constituiría solo un primer paso hacia las totalidades sistemáticas.

Las totalidades sistemáticas (distributivas) podrían presentarse, entonces, como efectos de una «recurrencia reflexiva» o re-totalización de las totalidades sistáticas, referidas al plano de las relaciones. Dado que al científico no le basta la mera observación, ha de demostrar que esas totalidades fenoménicas pueden ser representadas en diagramas análogos espaciales corpóreos. Esta es una característica decisiva para la definición de ciencia que le separa tanto de las pseudociencias como del teoreticismo: las estructuras sistemáticas que la Naturaleza «guarda ocultas» no se revelan a la mente o a la conciencia, sino a los dispositivos gráficos, a los aparatos de registro... Por ejemplo, las órbitas planetarias tendrán como referencia el sistema funcional de las cónicas: $A x 5+2 B x y+C y 5+2 D x+2 E y+F=0$. Esto es algo que ya vio Kant, en su lenguaje trascendental:

Aun teniendo en cuenta la multiplicidad de lo diverso, su afinidad bajo un principio de unidad se refiere mucho más a las propiedades y capacidades de las cosas que a éstas mismas. Por ello, si, por ejemplo, la órbita de los planetas se nos da como circular (en una experiencia no corregida todavía) y descubrimos que hay desviaciones, sospechamos éstas en aquello que puede transformar el círculo, de acuerdo con una ley constante y a través de infinitos grados intermedios, en una de estas órbitas divergentes; es decir, los movimientos planetarios no circulares se aproximarán más o menos a las propiedades del círculo desembocando en una elipse... (Kant, KrV A 662/B 690)

Si el planeta Júpiter percibido por el telescopio de Galileo puede definirse como una totalidad sistática de primer orden, se transforma en una totalidad sistemática que resulta de la proyección de las posiciones de una trayectoria espacio-temporal en el plano —papel, ordenador... - en el que la elipse se conforma. De modo que el científico no dirá que las curvas de Apolonio se proyectan sobre las órbitas planetarias, sino que son las posiciones de las órbitas las que se proyectan sobre el papel en el que la elipse ha de con-formarse (Fig. 5). De la misma manera que las ondas sísmicas se registran en líneas sinusoidales que traza la aguja grabadora sobre una carta. 


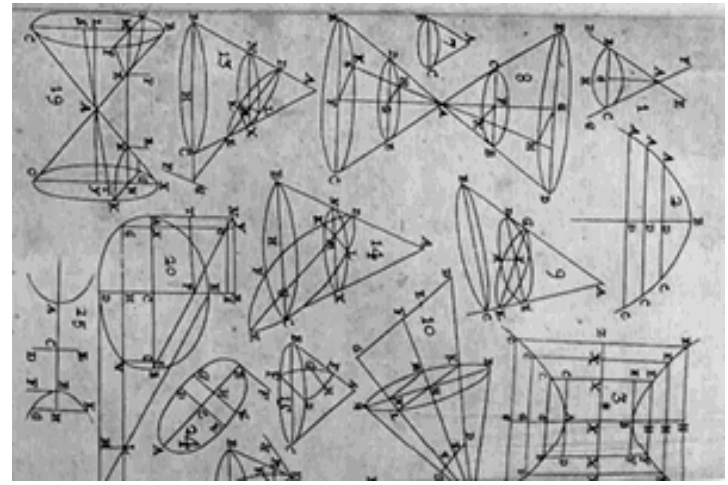

Fig. 5. Curvas sobre el papel en las que se proyectan las órbitas planetarias

La importancia del concepto de totalidad sistemática tiene que ver con la escala corpórea del sujeto que manipula todos estos aparato. La TCC se separa justamente aquí de la interpretación de Copenhague de la mecánica cuántica:

Las operaciones tienen siempre lugar en la escala macroscópica de nuestro cuerpo, de nuestros diagramas y aparatos; y la escala microscópica no «interactúa» con ellos (lo que equivaldría a hipostasiarla) sino que resulta de un regressus dialéctico a estructuras sistemáticas que, como el punto geométrico, dejan de ser corpóreas en sentido macroscópico. [TCC, vol. 2, p. 177]

¿Se encuentra aquí el límite de la TCC? Volveré a esta cuestión en el último parágrafo.

\section{PLURALIDAD CATEGORIAL}

El concepto de totalidad hay que incluirlo en la tesis más amplia de la pluralidad categorial. Las ciencias comienzan estableciendo relaciones por contigüidad, las totalidades sistáticas, que pertenecen a campos muy diferentes. Y como las totalidades están conformadas a distinta escala según características especiales, el alcance de cada ciencia implica la cuestión del alcance del campo categorial de esa ciencia en relación con otros campos categoriales, sus intersecciones, sus incompatibilidades, etc. GB realiza un estudio de la doctrina de las categorías realmente espléndido, al que remitimos al lector por su riqueza [TCC, vol. 2. pp. 53-262]. Conviene señalar que este factum de las ciencias, «república de las ciencias ejercidas», hay que entenderlo atributivamente: sus partes proceden de muy diversos lugares y tiempos. Ahora bien ¿por qué calificar esas prácticas como científicas? La respuesta original de GB es que la verdad científica no podrá residir ni en las teorías (sujeto o forma lógica) ni en los hechos (objeto o materia) ni en la correspondencia entre hechos y teorías, sino en la codeterminación de hechos y teoría: ahí radica el límite corpóreo y operacional humano. 


\section{VERDAD SINTÉTICA}

La verdad científica, por tanto, habrá de ser un resultado, no un desvelamiento (adversus Heidegger). La idea de verdad como identidad sintética que, indudablemente, procede de la tradición filosófica, no es una idea unívoca (una idea clara y distinta), sino analógica, porque contiene de modo conjugado la dualidad isología (relaciones metafóricas) / sinalogía (relaciones metonímicas), que, en el límite, alcanzan el grado de fusión plena. GB había mostrado en una obra anterior ${ }^{27}$ que las relaciones científicas se establecen cuando las relaciones de contigüidad se justifican independientemente de las de semejanza. Las identidades analíticas podrían reformularse en estos términos diciendo que la metáfora y la metonimia se han fusionado plenamente. El criterio de cientificidad, en consecuencia, se ha de someter a la siguiente regla: «Las relaciones por contigüidad habrán de verificarse independientemente de las relaciones por semejanza». Se descarta, en consecuencia, que las relaciones de contigüidad se soporten en las relaciones de semejanza. Veamos un ejemplo tomado del fisiólogo Xavier Bichat (1771-1802):

Pero un inmenso intervalo separa a la física y a la química de las ciencias de los cuerpos organizados (los organismos), ya que existe una enorme diferencia entre sus leyes y las de la vida. Decir que la fisiología es la física de los animales es dar una idea extraordinariamente inexacta; desearía decir que la astronomía es la fisiología de los cuerpos. (X. Bichat, Recherches physiologiques sur la Vie et la Mort, 1800)

En la proporción Fisiología (A) : Física (B) :: Animales (C) : Astros (D), los enunciados: «La fisiología es la física de los astros» es una relación tan impropia como «la física es la fisiología de los astros». ¿Por qué? Porque las relaciones metafóricas (A) / (B) y (C) / (D) han de verificarse con independencia de las relaciones metonímicas (A) / (C) y (B) / (D). Pero William Harvey ya había resuelto en 1630 esta relación de proporcionalidad. Al iniciar la argumentación que demuestra el teorema de la circulación de la sangre, apela a un contexto metafórico, una analogía Fisiología / Física:

Comencé a calibrar si no habría un movimiento como si dijéramos circular del mismo modo que Aristóteles dice que el aire y la lluvia emulan el movimiento circular de los cuerpos superiores.

\footnotetext{
${ }^{27}$ Gustavo Bueno, "Prólogo" a Eugenio Trias, Metodología del pensamiento mágico, Barcelona, Edhasa, 1970, pp. 9-36.
} 
Pero, inmediatamente después, corrige ese contexto metafórico por un contexto metonímico, e incorpora las relaciones de causalidad:

Y advirtiendo que no podía darse la cantidad necesaria de jugo de alimento ingerido para que NUESTRAS ARTERIAS REVENTARAN a consecuencia de la entrada excesiva de sangre si una parte de ella no volvía de nuevo de las arterias a las venas y al ventrículo derecho del corazón, empecé a reflexionar en mi interior si sería verdad que la sangre está en movimiento y que es arrojada del corazón e impelida a la periferia y a todas las partes del cuerpo a través de las arterias por el pulso del ventrículo izquierdo del corazón de la misma manera que lo es a los pulmones, a través de la vena arterial, por la pulsación del ventrículo derecho, como ya se ha visto... (W. Harvey, Exercitatio anatomica de motu cordis et sanguinis in animalibus, 1628)

Lo interesante del asunto es que la identidad, sea «esencial o sustancial», tiende a presentarse como identidad analítica. Precisamente la importancia gnoseológica de Kant, asimilada por la TCC, procede de haber eliminado de la ciencia los juicios analíticos - los juicios retóricos- y de hacer de los juicios sintéticos a priori la condición misma de la construcción científica. La identidad analítica se ofrece como la relación simple de un término consigo mismo, en el sentido de la sustancia (autos). Este límite (que es contradictorio, v. gr., la distancia cero) puede ser utilizado como límite revertido, es decir, el término límite elimina la estructura de la idea desarrollada en él al reaplicarse sobre tal idea, que es una forma de la metábasis reverberante. ${ }^{28}$

Pero las identidades sintéticas son de muchas clases y no todas ellas constituyen una verdad científica, pues depende de cómo se vinculen sinectivamente las partes. La sinexión es el vínculo ontológico que liga realidades o términos heterogéneos; este vínculo se mantiene entre distintos esquemas de identidad (elementos que permiten realizar la desconexión semántica), ${ }^{29}$ de modo que la identidad pueda seguir teniendo sentido.

\footnotetext{
${ }^{28}$ Gustavo Bueno, Cuestiones quodlibetales sobre Dios y la religión, Madrid, Mondadori, 1989, p. 319.

${ }^{29}$ Es tema interminable de polémica si esta desconexión epistemológica puede llevarse a cabo de manera clara y distinta. Muchos filósofo-sociólogos relativistas consideran, sin embargo, la imposibilidad de la eliminación de ese «residuo semántico», y estarían más en la línea de los paradigmas. Así, L. Wittgenstein, Observaciones sobre los fundamentos de las matemáticas, Alianza, Madrid, 1987; J. Ortega y Gasset, La idea de principio en Leibniz, Revista de Occidente /Alianza, Madrid, 1979; M. Foucault, Las palabras y las cosas, Siglo XXI, 1970; C. Castoriadis, Los dominios del hombre: las encrucijadas del laberinto, Gedisa, Barcelona, 1988; E. Morin. El método, vol. 4, Cátedra, Madrid, 1992...
} 
Las identidades sintéticas esquemáticas o configuraciones resultan de las operaciones sobre un núcleo sustancial. Por ejemplo, la identificación de la estrella matutina y de la vespertina se fundamenta en que las trayectorias de estos dos astros son prolongación analítica una de la otra. Estas identidades son constitutivas de los contextos determinados: «la línea recta» en geometría; «el movimiento inercial» en física...

Las identidades sintéticas sistemáticas o proposicionales constituyen relaciones y presuponen los contextos determinantes. Es este el tipo de identidades que constituye una verdad científica o relación de identidad esencial o sustancial, trascendental a los propios términos que ellas mismas logran trabar. Así pues, la identidad se resuelve: o en la identidad sustancial determinada por la confluencia de identidades esenciales de partes isológicas constitutivas del contexto sinalógico sistemático. Así: es el mismo sol el que brilla todos los días en el cielo [TCC, vol. 1, p. 162].

O en la identidad esencial determinada por la mediación de la identidad sustancial que se da en el contexto sinalógico sistemático. Por ejemplo, el teorema de igualdad de los ángulos opuestos [TCC, vol. 1, p. 163].

De manera que la elaboración de las identidades sintéticas en el proceso de conformación de las ciencias no puede ser considerado un suceso programable; ni la consecuencia de una metodología atinada; menos aun, el resultado práctico o teórico de una técnica. Si surgen en el seno de los diferentes procesos experimentales de reconstrucción de una parte de la realidad sometida a una serie de operaciones sistemáticas, es algo inesperado, muchas veces, consecuencia de la más trivial de las serendipias. Solo a través del análisis gnoseológico de una ciencia podemos remontarnos hasta los cursos operativos que han provocado, con su confluencia final, el resultado teórico que conocemos como teorema, teoría o ley. Un proceso que es fruto de multitud de operaciones y contextos experimentales, muchos de ellos inconcluyentes, de los que surgen relaciones, principios, y teoremas que abren el abanico de posibilidades de elaborar un conocimiento latente que creemos descubrir, pero que en realidad elaboramos con nuestras propias operaciones sobre las partes del mundo a las que tenemos acceso en cada momento. Como ha mostrado Antonio Casares (véase infra), el resultado final en la conformación de una ciencia como la química no se queda en estas estructuras convergentes derivadas de la experimentación. La estimación del Número de Avogadro fue, en cierto modo, un proyecto latente que permitió la unificación de la 
experimentación química, desarrollada bajo diversos esquemas morfológicos en una estructura final determinante: el contexto de modelización de la química moderna.

\title{
CONTEXTO DETERMINANTE
}

Las identidades sintéticas sistemáticas, tal es la tesis fuerte de la TCC, no se construyen ni en el polo del Sujeto ni en el polo del Mundo, sino en un campo trazado por un sujeto operatorio. Así, el oxígeno no será reconocido como una verdad necesaria ni en la perspectiva del Sujeto (incluido Dios) ni en la del Mundo, sino en la de un artefacto: la campana de Lavoisier [TCC, vol. 1, p. 182]. Pero tampoco parten del campo sin más, sino a través de ciertos términos entrelazados según esquemas de identidad, que forman ciertos «relieves» inmanentes al campo. Es este el motivo que posibilita la neutralización de las operaciones por medio de las cuales llegó a constituirse el sistema. Al entrelazamiento de al menos dos esquemas de identidad en condiciones adecuadas lo llama GB «contexto determinante» y es — junto con la identidad sintética - la gran aportación de la TCC. La TCC se opone frontalmente al tópico utilizado por Heidegger sobre el carácter absoluto de la ciencia y la filosofía. Que científicos y filósofos sueñen con que exista una verdadera VERDAD, el lenguaje de la verdad, el lenguaje de la realidad, es algo simplemente absurdo; nos encontraríamos en los territorios que podemos denominar "pseudofilosofía». ${ }^{30}$ El lugar de la verdad se encuentra justamente en el contexto determinante, que se constituye como tal verdad y así se conquistan racionalmente verdades necesarias sin que el científico haya de remontarse a principios absolutos:

\begin{abstract}
Ahora bien: la novedad que, a nuestro juicio, ha de considerarse decisiva, para la nueva teoría de la ciencia, tienen que ver con la evidencia de que hemos podido conquistar racionalmente verdades necesarias sin necesidad de remontarse a principios absolutos; es la evidencia de que bastan los principios categoriales, dados en la inmanencia de los cursos finitos, aunque inacabados (de procesos operatorios relativamente independientes, aritméticos, geométricos, mecánicos, termodinámicos, químicos, \&c.). Sólo desde perspectivas "proposicionalistas» estos principios categoriales o intermedios serán identificados con «hipótesis» o «proposiciones primitivas», principios internos (principia media). Desde una perspectiva gnoseológica no proposicionalista estos «principios categoriales» tienen que ver, ante todo, con la misma arquitectura del campo, con los contextos determinantes o «armaduras» que pueden construirse en él. (TCC, vol. 1, p. 50).
\end{abstract}

\footnotetext{
${ }^{30}$ Pseudo-filosofías existencialistas, místicas, gnósticas, totalizantes, represivas... Cf. F. M. Pérez Herranz, Árthra hê péphyken: Las articulaciones naturales de la filosofía, Universidad de Alicante, 1998.
} 


\section{Los géneros de la ciencia moderna: del Orden del cosmos (Aristóteles) a la desconexión potentia Dei absoluta y potentia Dei ordinata (Escoto y Ockham)}

La TCC, como decimos, se genera en las respuestas a la pluralidad de ciencias que se van formando a partir del siglo XIX. Por consiguiente, partimos de un concepto muy refinado de Ciencia. Ahora bien, el modelo potente de Ciencia se identifica habitualmente con el método hipotético-experimental, heredado de la mecánica moderna, alrededor de los dos grandes genios: Galileo Galilei e Isaac Newton. Pero es este método justamente el que se pone en cuestión con la aparición de la pluralidad de ciencias del siglo XIX, que no por retórica ha sido llamado «la era de la ciencia». ${ }^{31}$ Los criterios de cientificidad han de enfrentarse a las doctrinas del armonismo de las diferentes ciencias, como si conformaran un puzzle que se rellena con más o menos ingenio. El desarrollo de las ciencias en el siglo XIX pone en cuestión que el faktum de las ciencias sea homogéneo y armónico cuando aparecen ciencias alternativas. Así, la termodinámica se presenta rival de la mecánica newtoniana; la química, la microbiología, las geometrías no euclídeas son irreductibles a la mecánica; etc.

En todo caso, el modelo de la ciencia que asociamos a Galileo y Newton no sale de sus cabezas como Atenea de Zeus. Hay que entenderlo como un proceso de cristalización del novedoso concepto de ciencia que se origina en las polémicas y denuncias contra el aristotelismo pasado a través de las tradiciones árabes que llegaban ahora a Europa a través de Hispania, precisamente, en el periodo que suele denominarse despectivamente como «medieval». ${ }^{32}$ Polémicas, y aun persecuciones político-religiosas, respuestas al naturalismo griego que cuestionaba el modelo de un Dios creador de potencia infinita, del que se autonombraba vicario el papa de Roma. El universo asociado a este Dios inconmensurable con el hombre desbordaba completamente el orden del cosmos aristotélico. Por resumir rápidamente, frente a Aristóteles, que defendió un Cosmos, es decir, un mundo cerrado y ordenado, aunque no armónico, se levantó la revolución conceptual de Duns Escoto (1266$1308)^{33}$ que, ante el averroísmo aristotélico, desconectó la distinción tomista entre potentia Dei ordinata (con respecto a las leyes de la justicia divina y a las reglas de su sabiduría) y potentia Dei absoluta (con respecto de todo lo que no incluye contradicción) que era común

\footnotetext{
${ }^{31}$ David Knight, La era de la ciencia, Madrid, Pirámide, 1988.

${ }^{32}$ Un nombre que he denunciado en F. M. Pérez Herranz, Lindos y tornadizos. El pensamiento filosófico hispano (siglos XV-XVII), Madrid, Verbum, 2016.

33 Para André de Muralt, "la única revolución doctrinal digna de este nombre que se haya producido en la historia del pensamiento occidental". Cf. La apuesta de la filosofía medieval. Estudios tomistas, escotistas, ockamistas y gregorianos, Madrid, Marcial Pons, 2008, p. 155.
} 
en los medievales. La revolución escotista que supone la separación en la teoría del conocimiento entre el Sujeto y el Objeto, conduce a la posibilidad de un acto de conocer subjetivo, que defenderá Guillermo de Ockham, o de una representación objetiva, que defenderán Nicolas d'Autrècourt o Gregorio de Rímini. Un acto de conocimiento sin objeto, al eliminar la causalidad recíproca y total del sujeto y el objeto. De manera que ahora la cuestión de la potentia Dei absoluta nos conduce hasta la tesis de que Dios puede tener un conocimiento auténtico (legítimo y verdadero) de una cosa que no existe.

La filosofía moderna en su conjunto es un inmenso argumento ontológico en el que, habiendo suprimido la causalidad recíproca y total del sujeto y del objeto, se garantiza metafísicamente la correlación necesaria de la idea y de lo ideado, bien por creación paralela del orden de las esencias y las existencias (Descartes), bien por la unidad de la substancia (Spinoza), o bien por la armonía providencial divina (Leibniz). ${ }^{34}$

De aquí deriva la importancia de la Lógica en la filosofía de los siglos XIII-XV. Y su transformación epistemológica tras Galileo en la concepción de la ciencia como una relación entre teoría (lógica) y experiencia, entre momentos intelectuales (hipotéticos) y empíricos. ${ }^{35}$

\section{LOS PRINCIPIA MEDIA Y LAS ARMADURAS}

Pero el aristotelismo nunca desapareció. Hay una corriente científica que mantuvo la tensión y el rigor aristotélico. Hay una línea que va desde Gottfried W. Leibniz (1646-1716) hasta René Thom (1923-2002), pasando por Johann W. Goethe (1749-1832) o Henri Bergson (1859-1941), que es recelosa con las hipótesis y busca intermediarios morfológicos entre la experiencia y la teoría. En esta línea — tal como defendí en mi tesis doctoral— es en la que hay que situar el concepto de contexto determinante de GB, a partir de los principia media que había utilizado en La Metafísica presocrática:

En esta estructura se funda el concepto de principia media, del regressus hasta unos fundamento no últimos (...), pero necesarios y suficientes para que el progressus racional-categorial pueda tener lugar. ${ }^{36}$

\footnotetext{
${ }^{34}$ Ibidem, p. 116.

${ }^{35}$ La diferencia con Kant no se encuentra en la filosofía teórica sino en la filosofía práctica, que continúa la reflexión escotista y ockamista de la modernidad. Mientras que Kant condena violentamente la filosofía de la idea clara y distinta como «racionalismo dogmático», en la filosofía practica retiene la idea de la Ley como único principio formal del obrar moral, consagrando, desde el punto de vista trascendental, la alienación que la filosofía moderna había fundado sobre la omnipotencia divina.

${ }^{36}$ Gustavo Bueno, La metafísica presocrática, Oviedo, Pentalfa, 1974, p. 117.
} 
La TCC defiende la pluralidad de las ciencias contra una supuesta Mathesis universalis, una idea vinculada todavía a la ciencia divina, a una ciencia infinita y unitaria, que exige, para serlo, ser ciencia de lo necesario, de lo eterno. En la modernidad está vinculada a lo que GB llama la «inversión teológica»: entender un teorema es comprender el punto de vista de Dios, desde el cual se contempla el orden del mundo. ${ }^{37}$ El límite de esta idea no sería ya el sueño laplaciano de una ciencia determinista, pues Dios mismo habría sido absorbido por la Mathesis Universalis, sino el sueño fisicalista de un sistema formal fundado en el axioma que afirma la configuración original de todas las partículas en el principio de los tiempos, y del que se derivarían todos los teoremas del sistema: las configuraciones posibles que asumen las partículas en diferentes instantes de la historia del universo. ${ }^{38}$ GB ha hecho añicos esta idea de Mathesis Universalis al mostrar la inconmensurabilidad de las verdades, pues éstas pueden ser, incluso, peligrosas para la vida del propio hombre. No hay nada parecido a esa ingenua, armoniosa y confortable visión de la ciencia como una gran finca cultivada por científicos cada uno ocupado de su propia parcela sin interferir con las de los demás, esperando a lo sumo que nuevos terratenientes roturen y hagan productivas las tierras todavía yermas; más bien, y por decirlo radicalmente, la explosión de la bomba atómica en la parcela $x$ para verificar la ecuación de Einstein $e=m c^{2}$, puede dejar sin campo de trabajo a quien estudiara la formación de los atolones del Pacífico en la parcela $y$. Pues bien, para dar cuenta de las ciencias y sus inconmensurabilidades, se hacía necesario establecer algún elemento que permitiese explicar, por una parte, la naturaleza de la ciencia en general; $y$, por otra, la diferencia específica entre las distintas ciencias, incluida su posibles relaciones de inconmensurabilidad. Aquí radica, me parece, la potencia del concepto de contexto determinante de GB.

Los contextos determinantes se configuran, como se ha dicho, a partir de dos (o más) principios de identidad, que son enunciados sintéticos, imposibles de reducir lógicamente, propios de cada categoría e irreductibles a otras [TCC, vol. 2, p. 162] y cuyo entrelazamiento hace posible la neutralización de las operaciones que lo constituyeron. Así, el contexto determinante de triangulación, que veremos más adelante, está configurado a partir de los esquemas de identidad: la unidad de medida: el patrón en hierro que los expedicionarios habían traído consigo desde París: la toesa (1 metro y $946 \mathrm{~mm}$ ); y la base fundamental del

\footnotetext{
${ }^{37}$ Gustavo Bueno, Ensayo sobre las Categorías de la Economía Política, Barcelona, La Gaya Ciencia, 1972, p. 133.

${ }^{38}$ Por ejemplo, en Hofstadter (1987), p. 62.
} 
primero de los triángulos de la medición. Esquemas de identidad que son, a su vez, resultados de otros procesos de identidad sintética. Lo decisivo aquí es que la verdad no compete ni al sujeto (idealismo subjetivo) ni al mundo (realismo naturalista), sino a la armadura intermedia. Los contextos determinantes se encuentran, por tanto, en una posición epistemológica intermedia entre el nominalismo y el realismo. ${ }^{39}$

Las funciones de los contextos determinantes son múltiples. Entre otras, permiten demarcar la ciencia de lo que no es ciencia — protociencias, pseudociencias...—; demarcar la ciencia de otros saberes o procesos operativos no científicos —artísticos, tecnológicos...-; determinan los principios internos de las ciencias; establecen figuras o «planos secantes» con los que aprehendemos (y comprendemos) la realidad [TCC, vol. 3, pp. 133-4]. Lo que no significa que sean fáciles de hallar; al contrario, se requieren buenas dosis de ingenio para configurarlos [TCC, vol. 2, p. 344], sin olvidar las felices casualidades. Y, en definitiva, permite acceder a los teoremas, las unidades básicas de la ciencia que establecen relaciones de verdad. Los teoremas son formalizaciones derivadas de identidades sintéticas a partir de ciertos contextos aunque, además de ser conclusiones proposicionales, pueden dar lugar a clasificaciones o modelos. No sólo incluye un conjunto de $n$ proposiciones, sino términos, operaciones, relaciones, etc. (todas las figuras del eje gnoseológico). Y, más adelante, a partir del entretejimiento de «redes de teoremas», se constituye una teoría.

\section{GÉNESIS DE LOS CONTEXTOS DETERMINANTES}

El contexto determinante no es, en cualquier caso, un invento arbitrario o genial de GB, sino el resultado crítico de los conceptos construidos alrededor de los principia media. Aunque el término contexto determinante se encuentra cercano a la distinción de Hans Reichenbach (1938) ${ }^{40}$ entre contextos de investigación y de descubrimiento, el concepto se ha planteado ya en los inicios mismos de la investigación científica. El contexto de modelización pertenece a una estirpe muy sobria de la ciencia y de la filosofía de la ciencia. Su origen quizá haya que encontrarlo en la hipótesis o diorismós griega que sirve al matemático de supuesto o condición para obtener otra proposición sobre la cuestión planteada. El diorismós tendría su

\footnotetext{
${ }^{39}$ La autocalificación de GB como tomista es confusa. GB mira más bien a Francisco Suárez, que trata de armonizar al Aquinate y a Duns Scoto. He tratado a Suárez en "La modernidad de Francisco Suárez", José Luis Fuertes, Ángel Poncela, David Jiménez et al. (org.), La teoría filosófica de las pasiones y de las virtudes. De la Filosofía Antigua al Humanismo Escolástico Ibérico. Textos y estudios de Filosofía Medieval, 6. Edições Húmus, Riberão (Oporto), 2013, pp. 267-292.

${ }^{40}$ Hans Reichenbach, Experience and Prediction, University of Chicago Press, Chicago, 1993.
} 
razón básica en los métodos de aplicación de áreas, cuyas soluciones debían ser raíces positivas; para evitar las negativas era necesario limitar (diorízo) las condiciones del problema. Platón ofrece un ejemplo en el Menón (86e-87b), que, según la tesis de A. Heijboer, ${ }^{41}$ estaría resolviendo el siguiente problema: «Dado un rectángulo, si al levantar sobre su base una altura doble intersecta con la circunferencia, el triángulo formado por la base y los lados que unen sus extremos al vértice de la altura doble, será la mitad del rectángulo dado». El texto de Platón es el siguiente:

Y digo «a partir de una hipótesis tal como lo hacen frecuentemente los geómetras al investigar, cuando alguien les pregunta, supongamos, a propósito de una superficie, si, por ejemplo, es posible inscribir como un triángulo esta superficie en este círculo. Ellos contestarían así: «No sé todavía si esto es posible, pero, como una hipótesis, creo que puede ser de utilidad para el caso la siguiente: si esta superficie es tal que, al aplicarla sobre esa línea dada del círculo, le faltase una superficie igual a la que se ha aplicado, me parece que se ha de seguir un resultado, y si, por el contrario, es imposible que eso suceda, entonces se ha de seguir otro. Y así, pues, quiero yo hacer una hipótesis para ver qué resulta acerca de la inscripción de esta superficie en el círculo, si es posible o si no lo es.» Menón (86e-87b). (Fig. 6)

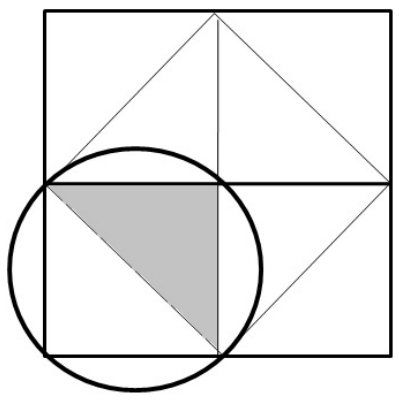

Fig. 6. Diorismós en el Menón (86e-87b)

El diorismós estaría asociado, en consecuencia, a salvar la teoría de los irracionales proporcionando un conjunto de esquemas de identidad construidos a partir de «la regla» y «el compás», sin apelar al misticismo, tal como explica el historiador Carl Boyer, quien, huyendo de los tópicos, ve en el uso de la regla y del compás por parte de Platón una cuestión de simetría: cualquiera de los infinitos diámetros de un círculo o cualquier punto de una recta es un eje de simetría de la figura. ${ }^{42}$ Aristóteles, que se mantiene en la tradición platónica, dice que los teoremas geométricos se descubren al realizarse en acto:

\footnotetext{
${ }^{41}$ A. Heijboer, "Plato «Meno» 86E-87a", Mnemosyne, volume 8, 1 (1955), pp. 89-22.

${ }^{42}$ Cf. C. B. Boyer, Historia de las matemáticas, Alianza, Madrid, 199 , p. 124.
} 
Lo encuentran, en efecto, al realizar las divisiones correspondientes. Y si las divisiones estuvieran ya realizadas, <los teoremas> serían obvios, pero están contenidos solamente en potencia. (Metafísica, 1051a22-25)

En otras ocasiones apela a una imagen que ha de acompañar al pensamiento: "Nunca el alma piensa sin fantasma", dice Aristóteles (De Anima, III, 7 y 8). ${ }^{43}$

Más tarde, Immanuel Kant vincula los conceptos del entendimiento y el material sensible a través de los esquemas trascendentales que podemos interpretar, como hace Roberto Torretti como una especie de método de coordenadas cartesianas, ${ }^{44}$ o Jean Petitot, que considera el juego kantiano desde una perspectiva trial: matemáticas-esquemasexperiencia y no dual: matemáticas-experiencia, de forma que los esquemas incorporan la imaginación matemática, mientras que los principios tendrían la responsabilidad de la explicación físico-matemática. ${ }^{45} \mathrm{O}$, dicho de otra manera, no ocurre que la matemática se aplique al mundo empírico, sino que éste se conoce matemáticamente. Con el desarrollo de las ciencias en el siglo XIX, esta imaginación trascendental se rompe en mil pedazos por los dominios de las técnicas, que darán paso a una enorme variedad de ciencias, cada una con sus propios enlaces entre la experiencia y la razón: electromagnetismo, química, termodinámica, teoría cinética de los gases...

De manera que el concepto de contexto determinante — como cualquier otro- está ya ejercitado de alguna manera en la reflexión de los científicos. Podríamos considerarlo como una sistematización del «símbolo material», al que se refería James Clerk Maxwell, para quien los esquemas de identidad se formarían por cuantificación:

Toda ciencia cuenta con algún instrumento de precisión propuesto por ella misma y que podría considerarse su símbolo material, pues permite a los observadores expresar sus resultados en forma de cantidades sujetas a medición. En astronomía tenemos el círculo dividido en partes; en química, la balanza, y en calor, el termómetro, mientras que la totalidad del sistema de la vida civilizada puede simbolizarse adecuadamente por medio de una regla de un pie, un juego de pesas y un reloj. ${ }^{46}$

\footnotetext{
${ }^{43}$ Castoriadis, "El descubrimiento de la imaginación", Constelaciones, vol. 1, nº 2, 1994.

${ }^{44}$ Roberto Torretti, "La geometría en el pensamiento de Kant", Logos. Anales del Seminario de Metafísica, volumen 9, 9 (1974), pp. 9-60.

${ }^{45}$ Jean Petitot, "Structuralisme et Phénoménologie: la théorie des catastrophes et la part maudite de la raison", editado en Logos et Théorie des Catastrophes, Patiño, Genève, 1988.

${ }^{46}$ J. C. Maxwell, Theory of Heat, Londres, 1872, p. 75, cf. en D. Cardwell, Historia de la tecnología, Madrid, Alianza, 1996, p. 21.
} 
Gilles Châtelet ha utilizado el concepto de «geste» para definir algo muy próximo a los contextos de modelización. ${ }^{47}$ El filósofo y científico francés, al exponer a Leibniz, se plantea dos cuestiones: ¿Por qué «milagro» los seres matemáticos, abstractos e inmutables se asocian a la determinación de los seres físicos sometidos a la contingencia y la movilidad? Y ¿Cómo reconciliar magnitud y cantidad? ¿Lo gradual y la cantidad? Y se pregunta: ¿Cómo atrapar el «gesto» físico-matemático? Gesto es un concepto que toma de J. Cavaillès ${ }^{48}$ y que está ejercido en G. Simondon ${ }^{49}$ y A. Leroi-Gurhan. Los ejemplos a los que recurre Châtelet — «el plano inclinado» de Galileo o «el ascensor» de Einstein, son del mismo tipo que los que utiliza GB: «plano inclinado», «balanza», «mesa de billar», «espectómetro», «cuerpo negro»...

Por otra parte, y argumentando por contraposición, observamos las dificultades que tiene Michel Serres para definir el artilugio inventado por Anaxágoras, conocido como gnomón. ${ }^{50}$ A veces lo asocia a una máquina, a un cálculo que no se reduce a demostración o a una razón algorítmica. Otras, lo define como «ciencia sin sujeto», ciencia automática, aquello que permanece objeto entre los objetos. En ocasiones realiza una paráfrasis: algo que se vuelve inteligente por su ubicación entre el suelo y el sol. Nosotros lo consideraríamos simplemente un contexto determinante por medio del cual se puede construir un modelo del universo. El artilugio, un simple estilete, al interceptar la luz del sol, va dejando huellas en la arena, como si escribiera en una página en blanco. No solo sirve para señalar la hora, sino para construir un contexto determinante que permita modelizar el mundo, un esquema cosmográfico del mundo. (Véase infra) $\varpi^{\infty}$

La misma dificultad la encontramos en Ilya Prigogine:

Pero los objetos de ciencia que seleccionaron los primeros físicos que emprendieron la matematización de los comportamientos naturales —el péndulo ideal de oscilación eterna y conservadora, la bala de cañón en el vacío, las máquinas simples de movimiento perpetuo, e igualmente las trayectorias de los planetas que son desde este momento asimiladas a seres naturales - todos estos objetos, a propósito de los cuales se realizó el primer diálogo experimental, se

\footnotetext{
${ }^{47}$ Gilles Châtelet, Les enjeux du mobile. Mathématique physique, philosophie, París, Seuil, 1993.

48 "Comprendre (une théorie) est en attraper le geste, et pouvoir continuer", Jean Cavaillés, Méthode axiomatique et formalisme, París, Hermann, 1938, p. 178.

${ }^{49}$ Gilbert Simondon, Du mode d'existence des objets techniques, París, Aubier, 1989.

50 Michel Serres "Gnomón: los comienzos de la geometría en Grecia" en M. Serres (ed.), Historia de las ciencias, Madrid, Cátedra, 1991, pp. 77-117.
} 
revelaron susceptibles de una única descripción matemática. Una descripción que reproducía precisamente la divina idealidad de los astros de Aristóteles. ${ }^{51}$

\section{DEFINICIÓN DE «CONTEXTO DETERMINANTE»}

Para fijar el concepto, ${ }^{52}$ podríamos definir un contexto determinante o de modelización mediante algunas notas intensionales, que son, a la vez, retos para la comprensión de la ciencia de nuestro tiempo, atrapada entre los dos polos del EXCESO que caracteriza lo humano: el crecimiento industrial sin límites y la necesidad de inteligibilidad del mundo.

En el ámbito de la Historia de las ciencias, los contextos determinantes muestran las razones por las que las ciencias no se desarrollan mediante los mismos ritmos. Es cierto que las ciencias de un período pueden mostrar un cierto «aire de época», pero pueden convivir ciencias que se encuentran en procesos y en períodos muy diferentes de «cristalización» (contra las epistemés de Foucault). La Historia de la ciencias vendría hilvanada, entonces, por los aparatos o los instrumentos, alrededor de los cuales se puede ir construyendo nuevas relaciones. Las grandes etapas del curso de cada ciencia estarían asociadas a equipos característicos de aparatos: mapas y figuras gráficas; esferas armilares, astrolabios, reloj de péndulo, anteojo y brújula; telescopio fotográfico, espectroscopio, interferómetro, radiotelescopio; sondas espaciales... Y, a partir de los años ochenta del pasado siglo, el uso generalizado del ordenador, que está siendo utilizado como contexto determinante en muchos campos de la ciencia. En palabras de Benoît Mandelbrot, vendría a ocupar el lugar tradicional del lápiz y la regla que habría agotado sus funciones:

Había un ancho hiato, de un centenar de años, en que el dibujo careció de función en matemáticas, porque la mano, el lápiz y la regla estaban agotados. Se entendían bien y habían quedado rezagados. Y el ordenador no existía.

Los contextos de modelización a los que el uso de los ordenadores permite acceder son muy abundantes, entre los que destaca, precisamente, la teoría de fractales del propio Mandelbrot. ${ }^{53}$ El surgimiento de los ordenadores ha introducido un giro espectacular en la conformación de los contextos de modelización, al poner de manifiesto con gran claridad que

\footnotetext{
${ }^{51}$ I. Prigogine e I. Stengers, La nueva alianza. Metamorfosis de la ciencia, Madrid, Alianza, 1983, pp. $254-255$.

${ }^{52}$ Cf. F. M. Pérez Herranz, "La filosofía de la ciencia de Gustavo Bueno", El Basilisco, n 26, 1999, págs. 15-42.

${ }^{53}$ Benoît Mandelbrot, Los objetos fractales, Tusquets, Barcelona, 1987.
} 
sus estructuras no son simples figuraciones o representaciones esquemáticas de la realidad, sino que producen un nuevo tipo: la realidad virtual. Las imágenes pertenecen al mismo proceso de investigación, constituido por esquemas de identidad que apuntan a relaciones de mayor alcance que la simple semejanza o analogía.

En el ámbito epistemológico de los criterios de demarcación. En primer lugar, entre ciencias y pseudociencias. $^{54}$ Los contextos determinantes permiten neutralizar el oscurantismo mágico: fantasías misteriosas o enigmáticas, espíritus astrales, extraterrestres, etc. Al alcanzar el contexto determinante, se eliminan estructuras ajenas a los términos del propio campo y su núcleo se nos hace inteligible [TCC, vol. 2, p. 183]. Los contextos determinantes se definen respecto de otros contextos que quedan prisioneros de. Por ejemplo, los rituales que utilizan los astrólogos, los videntes, los echadores de cartas, etc. (y cuya mención, incluso su estudio crítico desde la filosofía de la ciencia puede considerarse cualquier cosa menos carente de un alto interés y actualidad, dado el uso que las televisiones y las redes sociales hacen de esos personajes y de sus enseñanzas). Y ello sin perjuicio de que a veces los contextos de modelización pueden proceder de lugares muy extravagantes. Plinio cuenta una curiosa «historia» sobre Hipócrates. Según Plinio, Hipócrates "habría copiado de los exvotos de los templos datos en ellos consignados sobre los medios empleados para obtener la curación, sacando de allí luego la medicina". ${ }^{55}$

$\mathrm{Y}$ en segundo lugar, entre las ciencias y las técnicas. Alrededor de los aparatos o instrumentos — definidos como armaduras - se pueden ir construyendo nuevas relaciones de identidad. Desde esta perspectiva se valorará mucho mejor el ingenio de Galileo o de Faraday en la construcción de aparatos, que conducirán a la formulación de leyes fundamentales de la mecánica o del electromagnetismo. Alguien podría pensar que la ciencia se reduciría, entonces, a técnica. Pero este regressus a los orígenes tecnológicos exige después un progressus desde el momento tecnológico al científico, al núcleo de las verdades.

En este mismo ámbito epistemológico, los contextos determinantes deshacen algunos equívocos habituales: los aparatos no son «prolongaciones artificiales de los órganos humanos» (contra Spencer), el telescopio del ojo, o las máquinas extensión artificial de los

\footnotetext{
${ }^{54}$ F. M. Pérez Herranz, "La pseudociencia, contrafigura de la ciencia", Jornadas sobre superstición, creencia y pseudociencia. Cuando se apagan las luces de la razón, Oviedo, Sociedad Asturiana de Filosofía, 2003, pp. 79133.

${ }^{55}$ Hans Blumenberg, La legitimidad de la Edad Moderna, Valencia, Pretextos, 2008, p. 72.
} 
órganos del movimiento, sino operadores que transforman un conjunto de fenómenos en otros — a otra escala - y mediante los que se construyen muchos contextos determinantes [TCC, vol. 1, p. 119 y p. 343].

También en el terreno de la propia investigación científica. Si la ciencia es resultado de operaciones, es lógico pensar que los contextos determinantes se hayan construido en la escala de los cuerpos sólidos. Por eso, para acceder a fenómenos que no se dejen englobar en esa escala, como los fluidos, las turbulencias, los fenómenos meteorológicos, etc. se necesitarán contextos determinantes adecuados. Así se desarrollaría una de esas grandes intuiciones de Bergson:

Veremos que la inteligencia humana se siente en su casa en la medida en que se la deja entre los objetos inertes, especialmente entre los sólidos, donde nuestra acción halla su punto de apoyo y nuestra industria sus instrumentos de trabajo; veremos que nuestros conceptos han sido formados a imagen de los sólidos; que nuestra lógica es, ante todo, la lógica de los sólidos; que por eso mismo nuestra inteligencia triunfa en la geometría, donde se revela el parentesco del pensamiento lógico con la materia inerte y donde la inteligencia, después del más leve contacto posible con la experiencia, no tiene más que seguir su movimiento natural para ir de descubrimiento en descubrimiento... ${ }^{56}$

NOTA: Quizá podría reservarse el sustantivo de «armadura» para artefactos y el sintagma «contexto determinante» para estructuras más abstractas en torno a las cuales puedan ser determinadas las relaciones.

Y, en fin, los contextos determinantes tendrán la capacidad de neutralizar las declaraciones metafísicas sobre la totalidad del cosmos. Como hemos indicado, los contextos determinantes se encuentran limitados por los propios sujetos operatorios que los llevan a cabo —científicos, aparatos: telescopios, balanzas..., laboratorios...-, por lo que están siempre restringidos para su aplicación a la totalidad del mundo.

\section{CONTEXTOS DETERMINANTES ADVERSUS PARADIGMAS}

\footnotetext{
${ }^{56}$ Henri Bergson, La evolución creadora, Madrid, Espasa-Calpe, 1985, p. 9. Véase también René Thom, Modèles mathématiques de la morphogenèse, op. cit., p. 201
} 
Conviene hacer un comentario sobre el concepto de paradigma de Thomas Khun, ${ }^{57}$ contrafigura del concepto de contexto determinante. Ambos se asemejan por cuanto no consideran que un campo científico pueda ser tomado como tal en abstracto, como si fuese algo presupuesto, la realidad-en-sí, etc. Además, sitúan el análisis gnoseológico en ciertas escalas: instituciones históricas...

Pero se diferencian radicalmente en que mientras el paradigma se sitúa privilegiadamente en el eje pragmático, los contextos determinantes lo hacen en el eje semántico. Por una parte, el paradigma, que suele definirse como aquello que comparten los miembros de una comunidad científica, posee capacidad moldeadora respecto de otros sujetos gnoseológicos. Por eso hablar de paradigma es muy ambiguo, porque en ese concepto cabe cualquier cosa, no solo lo científico: ${ }^{58}$ lo artístico, lo religioso, lo político, etc. Ahora bien, por un lado, la ciencia exige determinar las estructuras específicas en función de la verdad; por otro, surge un problema complicado al tratar de definir el concepto de «sustitución de un paradigma por otro». ${ }^{59}$ ¿Qué quiere decir esto? Más que hablar de «cambio de paradigma», podría ser conveniente hablar de «transformación de una armadura en otra», o de «introducción de una nueva armadura capaz de reabsorber las anteriores». O, dicho de otro modo, no hay tanto «revoluciones científicas», como «nuevos contextos determinantes» [TCC, vol. 2, p. 307]. Si las revoluciones científicas comportan una connotación social, tendrán que ver más con los cambios que se producen en la escala institucional que en la escala interna de la ciencia. Las revoluciones, en este sentido, podrán darse en la filosofía, en las polémicas que generan las ciencias en las concepciones ontológicas, epistemológicas y éticas, pero no en las ciencias mismas.

Es cierto que las ciencias están recibiendo continuamente influencias ideológicas, político-administrativas, sociales, etc. Ahora bien, el contexto determinante se refiere a las propiedades internas, pues se segrega del medio desde dentro. Por eso puede combinarse con ideologías opuestas. Un ejemplo de esta ambigüedad está magníficamente narrada en una escena de la película de Alfred Hitchcock Cortina rasgada (1966), en la que un científico de la Alemania Oriental y otro de EE.UU, con propósitos subjetivos y políticos muy diferentes,

\footnotetext{
${ }^{57}$ La bibliografía sobre Thomas Kuhn es abundantísima. Como resumen, véase el reciente artículo de Gervasio Martos Valderrama, "Revolución científica: un acercamiento crítico a la actualidad del pensamiento científico kuhniano, Fragmentos de filosofía, 15 (2017), pp. 3-19.

${ }^{58}$ Como «paradigma» de esta concepción de paradigma, el popurrí con que, al alimón, nos obsequian Luis Racionero y L. Medina, El nuevo paradigma, PPU, Barcelona, 1990.

${ }^{59} \mathrm{G}$. Bueno, CC, p. 41.
} 
se encuentran resolviendo una ecuación diferencial, segregada totalmente de las ideologías de sus protagonistas. (Fig. 7)

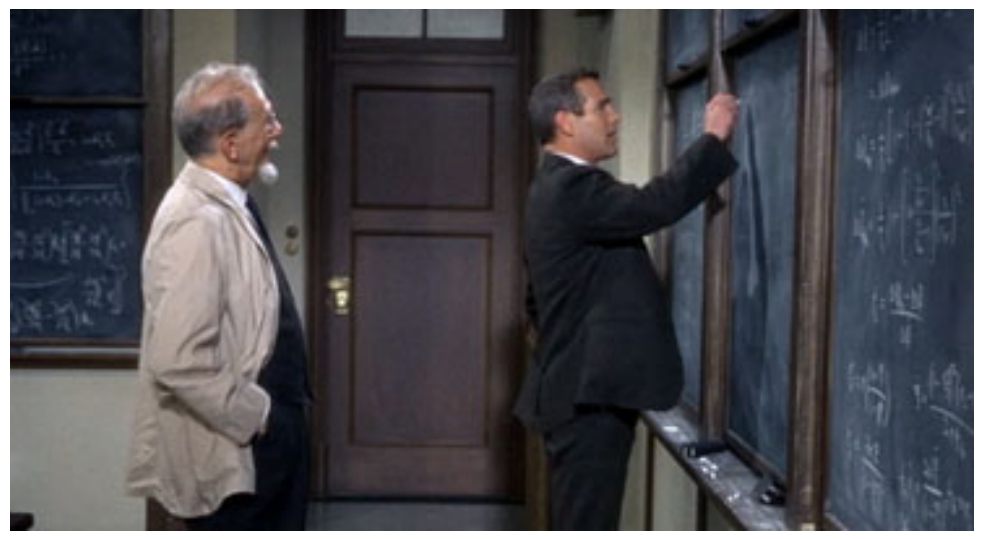

Fig. 7. El profesor alemán oriental Karl Manheim y el científico estadounidense Michael Armstrong

\section{Plano de la película Cortina rasgada de Alfred Hitchcock}

En otra ocasión, ${ }^{60}$ y con motivo de dar cuenta de «la irrazonable efectividad de las matemáticas para describir el mundo», del sorprendente paralelismo entre las fórmulas y la realidad, estudié el libro de Emmanuel Lizcano Imaginario colectivo y creación matemática. ${ }^{61}$ Como decía en el artículo mencionado, a las matemáticas chinas no se las habría de valorar gnoseológicamente por ser más humanas o moralmente más correctas (¿qué puede significar esto?) que las matemáticas griegas. La debilidad del argumento de Lizcano procedía, según argumentaba allí, en pasar abruptamente de las creencias a los teoremas y de la retórica a la razón. ${ }^{62}$ Ahora bien, para constituir la ciencia, para separarla de otros contextos mágicos, míticos o religiosos es necesario colocar en medio «la imagen» aristotélica, los «esquemas trascendentales» kantianos, el gesto, las armaduras..., que limitan y orientan el conocimiento. La falta de este mediador y la queja continua y sostenida de lo arrogante que es Europa con su Razón y sus cánticos a la pureza del saber ${ }^{63}$ es lo que molesta del libro que comentamos, por lo demás no solo lleno de extraordinario interés, sino muy necesario. $^{64}$

\footnotetext{
${ }^{60}$ Lo he tratado en el artículo citado "La eliminación de la subjetividad de los fines. Platón y las matemáticas".

${ }^{61}$ Emmanuel Lizcano Fernández, Imaginario colectivo y creación matemática, Gedisa, Barcelona, 1993.

${ }^{62}$ Ibidem, p. 154.

${ }^{63}$ Ibidem, p. 268.

${ }^{64}$ En cualquier caso, es esta una cuestión que va mucho más allá de la filosofía de la ciencia y, me parece, decisiva en nuestra época de globalización. Apuntaré muy rápidamente que incluso cierta mística, como la sufí, que también utiliza principia media, el término paralelo al de contexto determinante podría proceder del vocablo
} 


\section{Contextos determinantes clásicos}

Pero no cualquier cosa es un contexto determinante. GB hace una distinción sutil entre contexto determinante y contexto determinado. Éste es genérico, constituido por identidades sintéticas esquemáticas y, en consecuencia, poco fértil; todo lo más, permiten dar cuenta de los errores, pero no de las verdades. Los contextos que organizan los fenómenos en el eje semántico, se denominan colimadores. Por ejemplo: «el billar» es colimador del choque inelástico; «el juego de naipes» es colimador de la teoría de probabilidades; «el problema de Molineux» es colimador de la relación innato/adquirido; el par «emic/etic» es colimador de la Antropología o de la Lingüística...

Los contextos determinantes, sin embargo, son específicos del campo, y de ahí su potencia, y de la posibilidad de la verdad. Cuando en esos contextos determinados se logra establecer ciertas relaciones de identidad, que sirven de reglas de segregación o exclusión de relaciones inadecuadas, entonces podrán llamarse contextos determinantes, que se caracterizan por sus resultados y no por sus virtualidades a priori. Un contexto determinante, como hemos indicado, contiene al menos dos esquemas materiales de identidad, propios de cada categoría e irreductibles a otras [TCC, vol. 2, p. 162] y cuyo entrelazamiento hace posible la neutralización de las operaciones que lo constituyeron. Señalaré algunos:

— Triángulos, cuadrados, circunferencias y, en general, las figuras que consideró Ramon Llull [TCC, vol. 5, p. 138].

— El plano inclinado, la balanza, el pirómetro óptico...

—Ciertos dispositivos mundanos: la mesa de billar, el juego de dados [TCC, vol. 1, p. $107] \ldots$

—El principio de inercia, los tres primeros principios de Newton... [vol. 5, p. 140].

árabe qālib: molde o receptáculo, y que pasó al castellano como gálibo: "plantilla con la que se hacen las cuadres y otras piezas del barco". Cfr. Luce López-Baralt, A zaga de tu huella, Madrid, Trotta, 2006, p. 182. La diferencia entre la mística y la ciencia tendría que ver, entonces, con el uso de las relaciones metafóricas, comunes a la forma de pensamiento humano, y de las relaciones metonímicas, específicas del modo de pensar griego (Aristóteles-Euclides), vinculadas a la escritura algebraica, de carácter unidimensional. De manera que nuestra Semántica Topológica vendría a significar un puente entre el pensamiento oriental (La Thorá, El Corán..., la escritura china) y el pensamiento greco-latino. René Thom concluía su Estabilidad Estructural y morfogénesis (1977) de esta manera: "En este sentido, uno no puede dejar de admirar lo adecuado del sistema chino de escritura. En Occidente, la influencia dominante de la lengua hablada determinó una codificación silábica o alfabética [dominio de la lógica]; el significante se impuso brutalmente al significado [dominio de la topología]". Cfr. también, F. M. Pérez Herranz, Lenguaje e intuición espacial, Instituto de Cultura «Juan Gil Albert», Alicante, 1996. 
— El recinto vacío, el cuerpo negro... Espectrómetro, tubos de vacío, cuerpo negro...

["El cierre categorial aplicado a las ciencias físico-químicas", 1982, p. 147].

—Cono, campana de Lavoisier [TCC, vol. 1, p. 182], etc.

Recordaremos como ilustración tres contextos determinantes de gran relieve en la historia de las ciencias: «el triángulo», «el círculo» y «el gnomón».

\section{«EL TRIÁNGULO» EN TALES DE MiLETO}

El contexto determinante que podría pasar por ser el primero en instituirse es el triángulo, según el uso que hizo de él Tales de Mileto —y de ahí el acierto de Kant al situarlo en el inicio de las matemáticas—. ${ }^{65}$ En torno al triángulo pueden ser determinadas las relaciones de los teoremas de proporcionalidad. ${ }^{66}$ De manera que Tales podrá medir la altura de la pirámide estableciendo una proporción entre dos triángulos: uno, el formado por el bastón de nuestro filósofo-matemático, su sombra — por ejemplo, cuando sus longitudes sean iguales - y la línea virtual que une sus extremos; otro, formado por la altura de la pirámide, su sombra y la línea virtual que une sus extremos:

Jerónimo dice que Tales midió las pirámides según su sombra, observando el momento en el que nuestra propia sombra se iguala a nuestra altura. (Diógenes Laercio, Vidas de los filósofos más ilustres I, 27)

El triángulo se segrega ahora de las caras de las pirámides y, a partir de ahí, puede generalizarse a triángulos de todas clases con tal de que tengan un ángulo en común. No fue gratuito, sin duda, el que Tales de Mileto, adelantado de la ciencia y de la filosofía, realizase el excelente acto de piedad que relata el mismo Diógenes Laercio

Pánfila dice que Tales encontró la inscripción del triángulo rectángulo en el círculo, y que sacrificó por ello un buey.

\footnotetext{
65 "Una nueva luz se abrió al primero (llámese Tales o como se quiera) que demostró el triángulo equilátero. En efecto, advirtió que no debía indagar lo que veía en la figura o en el mero concepto de ella y, por así decir, a partir de ahí sus propiedades, sino extraer de éstas a priori por medio de lo que él mismo pensaba y exponía (por construcción) en conceptos" Immanuel Kant, Crítica de la Razón Pura, Madrid, Alfaguara, 1978, B XII.

${ }^{66}$ Véase el juego que da el triángulo equilátero en Bruno Munario, El Triángulo, México, Gili Gaya, 1999.
} 
En el papiro Rhind de Egipto, en algunas tablillas mesopotámicas, en los textos védicos, se encuentran procedimientos operacionales para trazar circunferencias o hallar el área del círculo. Tanto la circunferencia y el círculo como el triángulo estaban vinculados a determinadas técnicas —agricultura, agrimensura, arquitectura...— 0 a determinadas ceremonias —orientación de los altares para los sacrificios, danzas guerreras...- - El rey Salomón, por ejemplo, construyó una gran pila circular de bronce, de 10 codos de diámetro:

Hizo asimismo un mar de bronce fundido, de diez codos de un lado al otro, perfectamente redondo; y su altura era de cinco codos, y lo ceñía alrededor un cordón de treinta codos. (I Reyes 7, 23)

Ciudades como Cartago se construyen en emplazamientos circulares, etc. Pero siempre las figuras están asociadas al sujeto que las traza y al fin para el que se realiza. En Euclides, sin embargo, el mismo material concreto del mundo cotidiano desaparece, bloqueado por las definiciones, con las que comienzan los Elementos. ${ }^{67} \mathrm{El}$ espacio ya no es un espacio anterior al material (contexto determinado) que presenta el propio Euclides, sino un espacio que se delimita mediante las operaciones realizadas. En consecuencia, los postulados no se referirán al espacio religioso o al espacio agrícola, sino al espacio de las figuras concretas trazadas en el ámbito de los Elementos. Los tres primeros postulados son reglas operatorias (y los otros dos, en cierto modo, también):

1. Postúlese el trazar una línea recta desde un punto cualquiera hasta un punto cualquiera.

2. Y el prolongar continuamente una recta finita en línea recta.

3. Y el describir un círculo con cualquier centro y distancia.

4. Y el ser todos los ángulos rectos iguales entre sí.

5. Y que si una recta al incidir sobre dos rectas hace los ángulos menores que dos rectos, las dos rectas prolongadas indefinidamente se encontrarán en el lado en el que están los (ángulos) menores que dos rectos.

En Los Elementos el círculo se presenta como un esquema de identidad. Por ejemplo, el Libro I, proposición 1 dice: «Construir un triángulo equilátero sobre un segmento dado». Aquí ya ha desaparecido el sujeto operatorio; se ha neutralizado. Las figuras construidas están

\footnotetext{
${ }^{67}$ F. M. Pérez Herranz, "Entre Samos y el Museo: la travesía por el número y la forma geométrica", J. L. González Recio (editor), Átomos, almas y estrellas. Estudios sobre la ciencia griega, Plaza y Valdés Madrid / México, 2007, págs. 353-398.
} 
segregadas del sujeto operatorio que traza las líneas y van configurando un relieve en el campo sin mencionar al sujeto. Y en el libro III se estudia el círculo en sí mismo.

No es, pues, por milagro, sino por una exigencia interna al círculo mismo, por lo que el mundo concreto, cotidiano, existencial, desde el que se con-forma la figura geométrica, habría desaparecido por abstracción. Ese mundo se mantiene deliberadamente a distancia, bloqueado por las definiciones que lo describen, confinado a lugares precisos (las demandas o postulados), y en formas que canalizan sus ambigüedades y precisan su práctica ${ }^{68}$. El círculo, que se ha utilizado como esquema de identidad hasta el libro IV, comienza a ser utilizado como contexto determinante para construir un triángulo equilátero. Por contexto determinante se entenderá, entonces, algo que no puede probarse por una supuesta evidencia intrínseca evidencia o intuición-, sino por sus resultados. Los postulados sientan "las bases operativas de un procedimiento de construcción por regla y compás" dice Luis Vega. ${ }^{69}$

El círculo se encuentra en el inicio mismo de la astronomía y de la cosmología griegas. Parece que en Babilonia, a pesar de las observaciones muy precisas que realizaron de los cielos, no lograron organizarlas en un esquema geométrico; ni siquiera aparece el círculo. ${ }^{70}$ Pues el círculo (la esfera) no tiene arriba ni abajo, es autónoma, y no necesita ni de una tortuga ni de un elefante para sostenerse según la tradición hindú; el círculo (esfera) es una figura crítica, beligerante, contra las mitologías. Y que este análisis no es arbitrario queda corroborado cuando Platón mismo utiliza «la racionalidad» del círculo para demostrar la autonomía de la Tierra:

Aunque —prosiguió él— estoy convencido yo, lo primero, de que, si está en medio del cielo siendo esférica, para nada necesita del aire ni de ningún soporte semejante para no caer, sino que es suficiente para sostenerla la homogeneidad del cielo en sí idéntica en todas direcciones y el equilibrio de la tierra misma... (Fedón, 108e - 109a)

Una vez separados de su contexto — las prácticas de orientación física o espiritual—, el círculo y el triángulo, al irse haciendo autónomas las relaciones entre el círculo y su radio, y la proyección de un punto de la circunferencia sobre uno de sus radios (ángulos), que se toma como constante, han dado lugar a uno de los contextos más ricos y fértiles de relaciones

\footnotetext{
${ }^{68}$ Catherine Goldstein, "El uno es el otro: una historia del círculo" en M. Serres (ed.), Op. cit, pp. 158-159.

${ }^{69}$ Luis Vega, La trama de la demostración, Madrid, Alianza, 1990.

${ }^{70}$ Catherine Goldstein, "El uno es el otro: una historia del círculo", p. 162.
} 
geométricas. Toda la trigonometría se contiene en estas relaciones entre longitudes y ángulos, como puede comprobarse en la figura 8.

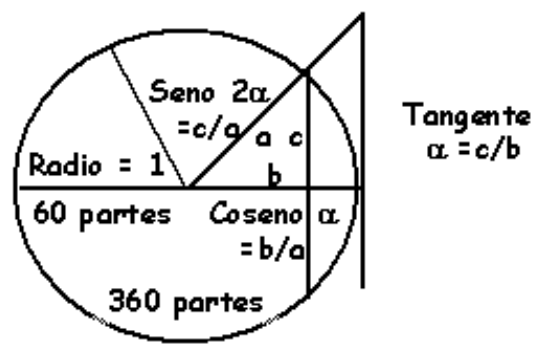

Fig. 8. Trigonometría

La trigonometría expresa el paso de la forma a la fórmula; es un caso ejemplar de la configuración del álgebra a partir de la medida de los lados de un triángulo y su relación establecida por el teorema de Pitágoras. Es decir, de un esquema de identidad: $d^{2}=b^{2}+c^{2}$. Estas relaciones trigonométricas pueden aplicarse después a otras partes del universo. Por ejemplo, al triángulo formado por el Sol, la Luna y la Tierra, pudiendo hallarse las distancias que separan unos astros de otros (Aristarco) o midiendo el radio de la tierra (Eratóstenes), etc. Ahora bien, obsérvese que si se quisiera aplicar al mundo como un todo, el contexto determinante se hipostasiaría como símbolo mágico. Por ejemplo: el movimiento circular como movimiento perfecto.

«EL GNOMÓN» DE ANAXIMANDRO

La potencia del contexto determinante puede comprobarse a través del artefacto conocido como gnomón. Ya hemos indicado las dificultades con las que se encuentra Michel Serres para definirlo (supra). El gnomón, al interceptar la luz del sol, va dejando huellas en la arena, como si escribiera en una página en blanco. No solo sirve para señalar la hora, sino para construir un contexto determinante que permita modelizar el mundo, un esquema cosmográfico del mundo. (Fig. 9) 


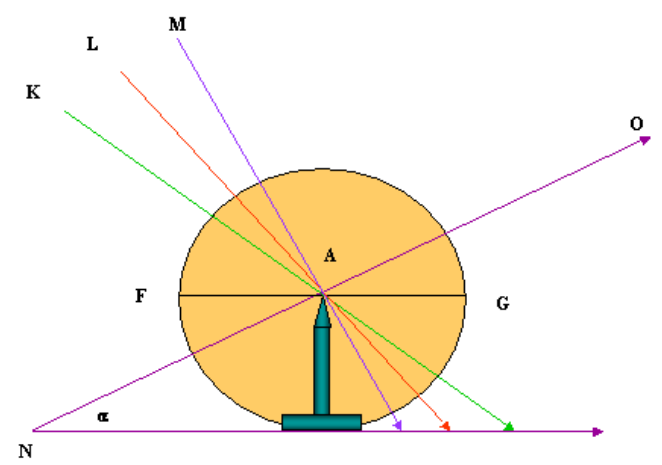

Fig. 9. El gnomón, contexto determinante

Este contexto determinante se fue desarrollando y fue absorbido por otros más fértiles, como las secciones cónicas de Apolonio (c. 262-190 aC), las de Girad Desargues (1591-1661) y Blaise Pascal (1623-1662), etc.

\section{Otros contextos de modelización}

De entre los contextos determinantes, de modelización o gnómicos que se han estudiado, he seleccionado otros tres, de los que haré una breve presentación: «la Teoría de las Catástrofes», «el Método de Triangulación» y «el Sistema Periódico para los Elementos». Concluiré con los problemas que surgen en una investigación científica al no dar con el adecuado contexto determinante para la formulación de ciertos teoremas que se buscan insistentemente, como ocurre en la Neurociencia.

\section{LA TEORÍA DE LAS CATÁSTROFES DE RENÉ THOM}

En mi tesis doctoral ${ }^{71}$ consideré la Teoría de las Catástrofes (TC) de René Thom como un contexto determinante para las ciencias biológicas. Cuando René Thom publicó Stabilité structurelle et morphogénèse, ${ }^{72}$ causó un gran desconcierto entre sus lectores. Para algunos la TC (a la que prefiero llamar Teoría de las singularidades topológicas) venía a sustituir nada menos que a la teoría clásica newtoniana; o, con más moderación, vendría a significar un cambio de paradigma. ${ }^{73}$ Para otros, era un simple teoría pura matemática; a lo que algunos

\footnotetext{
${ }^{71}$ Resumido en F. M. Pérez Herranz, "La teoría de las catástrofes de René Thom, nuevo contexto determinante para las ciencias morfológicas", El Basilisco, 16 (1994), pp. 22-42.

${ }^{72}$ René Thom, Stabilité structurelle et morphogénèse, Essai d'une théeorie générale des modèles, segunda edición en Intereditions, Paris, 1972. Modèles mathématiques de la morphogenèse, París, Ch. Bourgois, 1980.

73 Cfr. Tito Tonietti, "Inspired Mathematics or Applied Mathematics?...", Fundamenta Scientae, Vol. 2, 3/4 (1981), p. 328. "In this sense the CT controversy is the clash between incompatible paradigms; ... So there is no
} 
replicaban que era una simple teoría aplicada. También había quienes defendían que era una «forma de vida», que es una interpretación de la segunda época wittgensteiniana, en las antípodas de la ontología thomiana. Así lo sugiere J. Guchkenheimer ${ }^{74}$, extrañado ante las definiciones negativas que ofrece el propio Thom de la TC: "No es una teoría científica"; "No puede ser testada como una teoría científica". ${ }^{75}$ Tampoco podíamos aceptar que fuera simplemente un método, como a veces propone el mismo Thom. Allí defendí que la gran aportación de Thom era la de haber configurado un contexto determinante en el campo de la biología molecular, que es donde se inicia todo su compromiso filosófico (gnoseológico, ontológico y ético), aunque luego, por su propia naturaleza, pueda ser generalizado a otros campos científicos, los campos que tratan las morfologías. Pues como escribe el propio Thom: "Es el estudio del desenvolvimiento embriológico el que ha conducido a la creación de la teoría de las catástrofes". ${ }^{76}$ El contexto determinante que viene manejando la biología molecular es muy pobre, porque no es sino un contexto determinado: el de los procesos enzimáticos. ${ }^{77}$ Para nosotros esto significa que la TC irá desapareciendo, que incluso Thom quedará como una referencia erudita, porque estas figuras mismas se incorporarán sin más a la investigación $^{78}$, como ya lo hicieran el círculo, el triángulo rectángulo o la elipse.

\section{EL MÉTODO DE TRIANGULACIÓN}

En breve será publicado un artículo sobre el método de triangulación que fue utilizado en el siglo XVIII, que permitió determinar las medidas exactas del planeta Tierra en la expedición al Ecuador. ${ }^{79}$ En él muestro cómo el método de triangulación funciona como un contexto determinante, configurado a partir de los esquemas de identidad: la unidad de medida: el patrón en hierro que los expedicionarios habían traído consigo desde París: la toesa (1 metro y 946 mm); y la base fundamental del primero de los triángulos de la medición. En aquella enorme aventura que organizó la Académie des Sciences de París y en la que participaron nuestros Jorge Juan y Antonio de Ulloa, se formaron dos grupos para medir la base cada uno en sentido contrario. Luis Godin y Jorge Juan marcharon al llano de Cayambe;

doubt that CT in Thom's sense is incommensurable — in Kunh's sense - with many of the beliefs, values, and techniques to which the community of mathematicians and of applied mathematicians is so attached".

74 "Catastrophe Theory is a way of life", en John Guckenheimer, "The Catasptrophe controversy", Math. Intelligencer, 1 (1978), p. 16.

${ }^{75}$ René Thom, Apologie du logos, París, Hachette, 1990, p. 395.

${ }^{76}$ Ibidem, p. 341.

${ }^{77}$ Según la regla universal introducida por Beadie y Tatum: «Un gen, un enzima».

78 Así ya encontramos las cúspides sin cita de referencia en el libro de S. Hildebrtandt, y A. Tromba, Matemáticas y Formas óptimas, Barcelona, Prensa Científica, 1990, pp. 124-125.

${ }^{79}$ F. M. Pérez Herranz, "Jorge Juan: universalidad científica y particularidad nacional" (en prensa). 
y Pierre Bouguer, La Condamine y Antonio de Ulloa, al llano de Yaruquí. Tras múltiples avatares, propios de la condición humana, obtuvieron unas cantidades que tendían a una misma longitud: 6.272 toesas, 4 pies y 2 pulgadas y dos líneas, el grupo de Jorge Juan, y 5 pulgadas, el de Ulloa. Los valores encontrados en los tres grados de latitud medidos (unos 330 kilómetros) por los distintos equipos fueron casi idénticos: Juan y Ulloa hicieron públicos sus resultados en 1748 y hallaron 56.768 toesas para el grado; Bouguer en 1749, 56.763 toesas; y La Condamine en 1751, 56.768 toesas.

\section{EL Sistema de PERÍODOS PARA LOS ELEMENTOS}

Antonio Casares Serrano ha mostrado en su magnífica tesis doctoral ${ }^{80}$ la transición hacia un contexto de modelización de la química moderna en las primeras décadas del siglo XIX. En un brillante ejercicio de historia de la ciencia, muestra cómo a lo largo del siglo XVIII los químicos experimentalistas, a través del desarrollo de esquemas morfológicos como la balanza, el gasómetro y el calorímetro, alcanzaron una serie de «leyes ponderales» que abrían las puertas a una modelización de la estructura de la materia mucho más elaborada que las propuestas desarrolladas desde la filosofía natural. Se detiene en el debate entre John Dalton (1766-1844) y Louis Joseph Gay-Lussac (1778-1850), que llegaban a conclusiones experimentales similares, pero que no zanjaban la cuestión sobre la química. La razón de esta disputa se encuentra en que el contexto de modelización de la química moderna no estaba todavía plenamente elaborado, porque faltaban algunos nuevos esquemas morfológicos por desarrollar: el procedimiento de descomposición electroquímica, introducido en 1800 por William Nicholson y Anthony Carlisle; el análisis electroquímico, derivado de la pila de Volta, que planteaba nuevos desafíos teóricos; el concepto de «equivalente electroquímico» de Faraday, etc. Casares va mostrando la eficiencia de los esquemas morfológicos ya consolidados de la nueva química, que apuntaban hacia alguna confluencia latente entre los resultados gravimétricos y volumétricos que pudiera resolverse en un modelo de atomicidad experimental. Presenta, entonces, la teoría atómica de Dalton como una teoría de la discontinuidad material a partir de la que podían explicarse todas «las leyes ponderales» derivadas de la experimentación cuantitativa. Los químicos de la primera mitad del siglo XIX contaban con una considerable pericia experimental y con un abundante bagaje de datos empíricos tabulados en secuencias numéricas, pero carecían de modelos representativos de la

\footnotetext{
${ }^{80}$ Antonio David Casares Serrano, Morfologías de la materia. Análisis gnoseológico de la teoría atómica moderna, Universidad de Alicante, 2016.
} 
dinámica química como los que en su momento propusiera el mecanicismo del siglo XVII. Estos modelos ya no eran operativos porque se desentendían de gran parte de los resultados experimentales y, además, eran incapaces de reflejar la naturaleza de la estructura de las sustancias, su reactividad —más allá de un concepto tan literario como «la afinidad»—, así como su estabilidad. No obstante, el desarrollo de amplios marcos experimentales era una condición necesaria pero no suficiente para la elaboración de una teoría atómica que sostuviera la conformación de la ciencia química. Así lo dice expresamente el autor:

Como acabamos de ver, en las articulaciones finales de la ley de periodicidad, con Dmitri Mendeleiev y Lothar Meyer, la química alcanzaba el estatus final de ciencia a partir de lo que hemos denominado un contexto de modelización. ¿Qué hace de la organización de los elementos químicos en períodos una estructura teórica singular? ¿Podemos considerar la tabla periódica de los elementos como una simple clasificación aunque de un nivel más elaborado que las tablas de afinidades? Creemos que, a estas alturas de nuestra investigación, podemos considerar que la organización de los elementos químicos en períodos constituye el paso final del proceso de conformación de la ciencia química y labase del marco general en el que esta ciencia desarrollará su actividad posterior. La constitución del campo de la química descansa en la ley de periodicidades de los elementos que constituye el punto de partida para la aceptación de la teoría atómica moderna desde los esquemas morfológicos de la ciencia moderna. A partir de la articulación de la tabla de períodos de los elementos, la química se constituye en campo de conocimiento sistemático, en contexto de modelización desde el cual ampliar el alcance operativo de su actividad constructiva reorientada hacia la síntesis de nuevos materiales. ${ }^{81}$

\section{AUSENCIA DE CONTEXTOS DETERMINANTES EN LA NEUROCIENCIA}

El éxito de la Biología Molecular con el descubrimiento del «teorema de la doble hélice» y todos los proyectos de investigación que ha arrastrado, entre los que sobresale The Human Genoma Project (HGP) ha servido de estímulo para la investigación del cerebro, que ha propuesto también un The Human Brain Project que imita descaradamente al primero. En un artículo de $2010^{82}$ he estudiado esta ausencia de un teorema en neurobiología que tuviese la potencia del teorema del ADN y la dificultad de alcanzar un adecuado contexto determinando. Lo que pretendí mostrar en este ensayo es que la investigación neurocientífica se encuentra en un estadio en el que hay profusión de datos fenoménicos, penetrantes relaciones entre términos neuronales, refinadas operaciones en el interior del cerebro y hasta

\footnotetext{
${ }^{81}$ Ibidem, p. 359.

${ }^{82}$ F. M. Pérez Herranz, "El teorema de la conciencia y el Proyecto Cerebro Humano” en F. J. Serrano Bosquet (ed.), Ciencia, Tecnología y Sociedad, México, MacGraw Hill, 2010, pp. 217-240. Una revisión del artículo en "La Conciencia: ¿especulación ideológica o teoría científica?", Eikasía, 76 (2017), pp. 9-51.
} 
sugestivos esquemas de identidad sobre neurotransmisores, localización craneal y evolución neurofisiológica; mas no se ha encontrado aún el teorema de la conciencia. Este vacío que se soslaya con hipótesis ad hoc, más o menos ingeniosas. La incógnita del problema por resolver quedaría despejada si se encontrara al menos un modelo o estructura que permitiera entrever el teorema. De manera que, a diferencia de la biología molecular, que ha hecho desaparecer todas las opiniones, hipótesis o teorías que se proponían sobre la herencia con anterioridad al descubrimiento del ADN —-pangénesis, preformismo, vitalismo, plasma germinal...-, las hipótesis de los neurobiólogos (eventualmente de los neurofilósofos) ${ }^{83}$ que se atreven a ofrecer una respuesta únicamente pueden tomarse como una opción más o menos sensata o razonable.

\section{Los límites de la TCC: entre la gnoseología materialista y la epistemología fenomenológica}

La formación de las ciencias naturales «clásicas» se dejan analizar sin violencia alguna por medio de los conceptos de la TC: contextos determinantes e identidades sintéticas. Las ciencias humanas, por su parte, si bien no admiten el cierre categorial, por la imposibilidad de eliminar al sujeto de las operaciones, pueden analizarse por medio de la distinción entre metodologías alfa-operatorias y beta-operatorias. En las primeras se neutraliza el sujeto operatorio que permanece incorporado en las segundas. Por ejemplo: en Lingüística se pasaría desde los niveles de la Lingüística Aplicada $\left(\beta_{2}\right)$ y de la Sintaxis (Chomsky) $\left(\beta_{1}\right)$ a otros más propios de las ciencias naturales: la Morfología (Saussure) $\left(\alpha_{2}\right)$ y, en el límite, la Cibernética $\left(\alpha_{1}\right)$. Pero la cuestión se hace mucho más difícil, si no imposible, en el caso de la mecánica cuántica. A partir de los hallazgos de Max Planck (1858-1947) sobre la radiación del cuerpo negro, con los que se inicia la cuantización; la radiación del fondo cósmico de microondas descubierta por Arno Penzias y Robert W. Wilson; o la definición de fotón de Albert Einstein (1879-1955) como «cuanto de luz» se puso en entredicho el marco de la física clásica que ya venía había sufrido crisis muy profundas en matemáticas desde la formalización de las geometrías no euclidianas. Una revolución de esta naturaleza y magnitud en la ciencia tenía que perturbar también a la propia filosofía de la ciencia. Así que es lógico preguntarse: ¿Cómo afecta este nuevo marco de la física a la gnoseología materialista de la TCC?

\footnotetext{
83 "El materialismo no es un hecho establecido como lo es el teorema del ADN", reconocen P. S. Churchland y T. J. Sejnowski, The computational brain, MIT Press, Cambridge, Massachussets, 1990.
} 
Una pregunta que ha planteado el discípulo más avezado de GB, Ricardo Sánchez Ortiz de Urbina. Me remito a sus investigaciones: la Estromatología, ${ }^{84}$ que sintetiza un trabajo muy riguroso, desgranado en artículos y conferencias; ${ }^{85}$ y la Epistemología fenomenológica, en preparación. ${ }^{86}$ Ortiz de Urbina considera que tal vez sea el principio de Pauli la última estructura analizable en los términos de la TCC. Lo que está más allá de la escala habitual, la organización de la materia sin más principio que el de la conservación de la energía, queda fuera del dominio clásico. Mantener las explicaciones clásicas, señala, equivaldría a permitir la catástrofe de la materia. Entre otros muchísimos aspectos de enorme interés, Urbina ha puesto en cuestión el concepto de Sujeto que va asociado a la TCC, pues, como cualquier otro fenómeno, el Sujeto está sometido a la indeterminación. El Sujeto no queda fuera del análisis: es la propia subjetividad la que resulta medida y estratificada en niveles. Recuerda Urbina cómo las dos grandes revoluciones conceptuales, en Física y en Filosofía, son coetáneas, y cómo se aprecia una sorprendente convergencia de los procesos de desnaturalización tanto en matemáticas — Hilbert— como en filosofía — Husserl—. ${ }^{87}$ En un amplio y profundo estudio, que aquí no podemos sino citar e invitar al lector a su estudio (no sirve una somera lectura) apela, entre otros conceptos, a los llamados «caminos de Feynman» que le permiten explicitar el concepto fenomenológico de transposibilidad, un concepto que vendría a ser el paralelo al concepto de superposición (Gato de Schrödinger) en mecánica cuántica. La transposibilidad permite neutralizar el proceso de la formación de verdades científicas «clásicas» o identidades sintéticas. En mecánica cuántica las predicciones, incluso las probabilidades, desaparecerían; lo que hay son amplitudes de probabilidad, que son transposibilidades en el lenguaje fenomenológico. En las transposibilidades se producen saltos, pero no de identidad a partir de un nivel dado, sino como un nivel de base a partir del cual se alcanza el nivel inferior, que es el nivel de la vida y de la ciencia, el nivel objetivo, perceptual y operatorio (al modo de los caminos cuánticos que alcanzan el nivel de los objetos cotidianos). ${ }^{88}$ La pregunta que puede hacerse desde la TCC es, entonces, de este tenor:

\footnotetext{
${ }^{84}$ Ricardo Sánchez Ortiz de Urbina, Estromatología. Teoría de los niveles fenomenológicos, Brumaria, Madrid, 2014.

${ }^{85}$ Por ejemplo, "Principio de Correspondencia", Eikasia, 56 (2014), pp. 9-30. "Abyssus Abyssum invocat: la matemática entre la intentio y el eidos", Eikasia, 72 (2016), pp. 19-35, etc.

${ }^{86}$ Algo insinuó en su conferencia "Del materialismo filosófico al materialismo fenomenológico", en el Congreso Filosofía en Asturias: la escuela materialista de Oviedo, 2016, organizado por la Sociedad Asturiana de Filosofía.

${ }^{87}$ Las vidas de David Hilbert (1862-1943) y de Edmund Husserl (1859-1938) fueron estrictamente coetáneas. Coinciden en Göttingen, centro de la investigación matemática de la época, durante once años (1905-1916), antes de que Husserl se trasladase a Friburgo.

${ }^{88}$ En otra ocasión propuse el siguiente texto de Didi-Huberman para ejemplificar el concepto de transposición. Reflexiónese en cómo va pasando desde las cortezas de los abedules al horror de las cámaras de gas: "En el sentido más estricto, el recuerdo verdadero debe dar, de un modo épico y rapsódico, una imagen de quien
} 
¿pueden seguir siendo eficaces los contextos determinantes en la mecánica cuántica? Desde luego este es el reto para los seguidores del materialismo filosófico de GB. (Y me atrevería a decir más: «O el núcleo de la filosofía de GB es la TCC, o no será»)

Desde mi perspectiva, los contextos determinantes pueden seguir siendo la clave para la organización de las verdades científicas, incluidas las de la mecánica cuántica. Tomemos como punto de partida los diagramas de Richard Feynman, tal como los ha estudiado Luciano Boi. ${ }^{89}$ Estos diagramas son representaciones simbólicas (conceptos gráficos) que permiten no solo calcular las interacciones electromagnéticas y las interacciones débiles, sino también «visualizar» las interacciones entre partículas elementales. Así, por ejemplo, un protón puede escindirse para formar un pion y un neutrón que se reabsorben, poco tiempo después, para reformar el protón original. De manera general, los diagramas de Feynman describen los procesos que tienen lugar entre las partículas subatómicas. (Fig. 10)

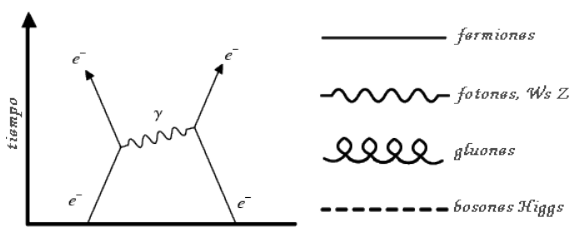

Fig. 10. Diagramas de Feynman

Ahora bien: ¿¿Son estos diagramas exclusivamente «visualizaciones» o son algo más? ¿Permitirían intervenir en el proceso de descubrimiento? ¿Darían lugar a la formulación de teoremas? En los años cincuenta y sesenta del pasado siglo se desarrollaron problemas que venían planteándose por una vía distinta a la mecánica cuántica, que se denominó de distintas maneras: teoría del caos, teoría de bifurcaciones y singularidades, teoría de la complejidad... nombres que estuvieron sometidos a una enorme contaminación por la publicidad que se dio en los medios de comunicación no específicamente científicos. Fue una respuesta a la cuestión que se había iniciado en el siglo XIX con el conocido como problema de los tres

recuerda, así como un buen informe arqueológico debe indicar no solo las capas de donde provienen los descubrimientos, sino también y sobre todo las que fue necesario atravesar para llegar a ellos" (...) "Es lo que la corteza me dice del árbol. Es lo que del árbol me dice el bosque. Es lo que el bosque, el bosque de abedules, me dice de Birkenau...". George Didi-Huberman, Cortezas, Shangrila, Santander, 2014, págs. 63 y 65.

${ }^{89}$ Cf. Luciano Boi, Morphologie de l'invisible, Presses Universitaires de Limoges, 2011. Juan Arana, Los sótanos del universo, Madrid, Biblioteca Nueva, 2012. F. M. Pérez Herranz, "Llamando a las puertas del universo", Eikasía, 54 (2014), pp. 179-206. 
cuerpos. $^{90}$ Resumido muy rápidamente: aunque las ecuaciones que gobiernan los movimientos de tres partículas no parecían más complicadas que las que rigen los movimientos de dos partículas, los movimientos resultantes, sin embargo, son enormemente complicados. H. Bruns y H. Poincaré demostraron que "no había soluciones de la clase que los matemáticos habían buscado", 91 porque el lagrangiano resta la energía cinética y la potencial y utiliza las coordenadas espaciales y la velocidad: su integral está en función no del tiempo, sino de la acción; no es el tiempo clásico, sino el tiempo continuamente haciéndose, puramente irreversible, y define el espacio de configuración, $\mathrm{E}_{\mathrm{C}}{ }^{92}$

Pues bien, Richard Feynmann en su teoría Quantum Electro-Dynamics (1948) ha seguido el lagrangiano, con este matiz: en la mecánica clásica el lagrangiano determina el camino correcto - pues al tener la probabilidad 1 se convierte en el camino correcto- y asigna al resto de posibles caminos la probabilidad 0; en mecánica cuántica, un dominio de amplitud de probabilidad, de lo trasposible (no de lo posible), los caminos son transitados simultáneamente (Fig. 11).

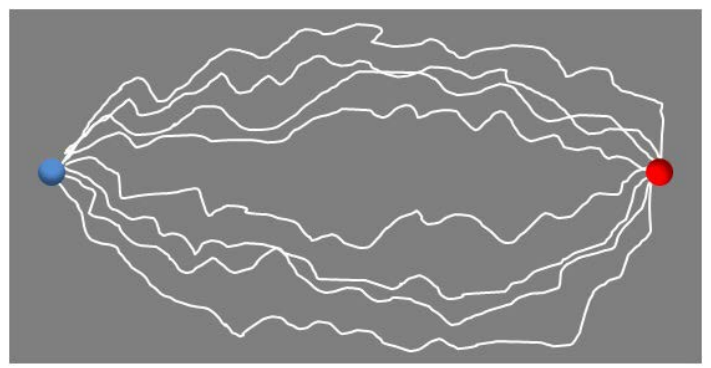

Fig. 11. Caminos de Feynman

Todos los caminos contribuyen al resultado que se busca, con un peso proporcional a la acción total de cada camino. Pero esto es justamente lo que es pensar, dice Ortiz de Urbina: en la búsqueda del sentido trasposible se recorren simultáneamente los caminos que exploran lo imprevisible, en un tanteo conjunto en el que oscilan y se ajustan los pesos de sus probables trasposibilidades. (Un tema que abre una constelación nueva de problemas a la reflexión

\footnotetext{
${ }^{90}$ Alexis Claude Clairaut propuso cambiar la fórmula de Newton: $F=g \cdot m \cdot m^{\prime} / d^{2}$, por otra más compleja: $F=g \cdot m \cdot m^{\prime} / d^{2}+g^{\prime} \cdot m \cdot m^{\prime} / d^{4}$, porque no recogía los movimientos de la Luna con exactitud. La desviación está motivada por la perturbación que se produce cuando intervienen tres cuerpos en movimiento.

${ }^{91}$ D. Layser, Construcción del universo, Barcelona, Labor, 1989, p. 100. Cfr. también J. Laskar, y Cl. Froeschlé, "El caos en el sistema solar", en Mundo científico, n 115, 1991.

${ }^{92}$ Cf. V. I. Arnold, Mecánica clásica. Métodos matemáticos, Madrid, Paraninfo, 1983; Ecuaciones diferenciales ordinarias, Madrid, Rubiños, 1995; Singuaridades de cáusticas y de frentes de ondas, Madrid, Rubiños, 2000. V. I. Arnold, A. Varchenko y S. Goussein-Zadé, Singularités des applications différentiables. I. Classification des points critiques, des caustiques et des fronts d'onde, Moscú, Mir, 1986.
} 
filosófica y, de manera muy especial, el paso del sujeto operatorio al ego transoperatorio, que permite dar el salto de la identidad intencional —en el lenguaje de la fenomenología — a la identidad sintética de las verdades de la ciencia clásica), precisamente por su capacidad de sintetizar determinadas fantasías perceptivas (la variación eidética de la fenomenología, cercana al contexto determinante del materialismo). Así se puede acceder al campo eidético, organizando unas estructuras cada vez más profundas y unitarias (aquí he de remitir obligatoriamente a los trabajos de Ortiz de Urbina).

En consecuencia, en el caso de los diagramas de Feynman, pero también en los diagramas de la teoría de nudos, en los diagramas de la electrodinámica cuántica, etc., los diagramas no se utilizan simplemente para ilustrar algo —objetos o sucesos—, sino más bien como operaciones simbólicas (podría decirse: operadores) de naturaleza algebraica. Más aun: los diagramas permiten mostrar y conocer propiedades topológicas, por ejemplo, del objeto nudo que conciernen especialmente a sus posibles transformaciones en el espacio y sus características invariantes. Por otra parte, una vez conocidas, estas propiedades topológicas pueden conducir al descubrimiento de nuevas invariantes algebraicas de los nudos. ${ }^{93}$ Es decir, que ciertas técnicas de visualización, especialmente los diagramas, se constituyen en dos niveles de representación: el primero corresponde a modelos de objetos reales en tanto que son imaginados y no directamente observados; el segundo, concierne a los elementos que forman los modelos ellos mismos, es decir, los aspectos gráfico, denotativo y connotativo. Desde este punto de vista, los diagramas (como las imágenes, los dibujos, los grafos...) permiten «ver» lo que no es visible, por una creación de objetos que encierran propiedades de acontecimientos y de nuevas articulaciones de sentido. En este sentido, el concepto de contexto determinante serviría de puente entre el materialismo gnoseológico de GB y la epistemología fenomenológica de Sánchez Ortiz de Urbina.

93 Cf. Luciano Boi, Morphologie de l'invisible, Presses Universitaires de Limoges, 2011. Juan Arana, Los sótanos del universo, Madrid, Biblioteca Nueva, 2012. F. M. Pérez Herranz, "Llamando a las puertas del universo", Eikasía, 54 (2014), pp. 179-206. 